\title{
Myocardial perfusion imaging in women for the evaluation of stable ischemic heart disease- state-of-the-evidence and clinical recommendations
}

\author{
Viviany R. Taqueti, $M D, M P H,{ }^{\mathrm{a}, \mathrm{b}}$ Sharmila Dorbala, $M D, M P H,{ }^{\mathrm{a}, \mathrm{b}}$ David Wolinsky, \\ MD, ${ }^{\mathrm{c}}$ Brian Abbott, MD, ${ }^{\mathrm{d}, \mathrm{e}}$ Gary V. Heller, MD, PhD, ${ }^{\mathrm{f}}$ Timothy M. Bateman, MD, ${ }^{\mathrm{g}}$ \\ Jennifer H. Mieres, $M D,{ }^{h}$ Lawrence $M$. Phillips, $M D,{ }^{i}$ Nanette K. Wenger, MD, ${ }^{j}$ \\ and Leslee J. Shaw, PhD \\ a Noninvasive Cardiovascular Imaging Program, Departments of Medicine and Radiology, \\ Brigham and Women's Hospital, Boston, MA \\ b Division of Nuclear Medicine and Molecular Imaging, Department of Radiology, Brigham and \\ Women's Hospital, Harvard Medical School, Boston, MA \\ c Department of Cardiovascular Medicine, Cleveland Clinic Florida, Weston, FL \\ d Warren Alpert Medical School, Brown University, Providence, RI \\ e Cardiovascular Institute, The Miriam and Newport Hospitals, Providence, RI \\ f Gagnon Cardiovascular Center, Morristown Medical Center, Morristown, NJ \\ g Saint Luke's Health System, University of Missouri-Kansas City School of Medicine, Kansas \\ City, MO \\ h Hofstra Northwell School of Medicine, New York, NY \\ i Leon H. Charney Division of Cardiology, New York University Langone Medical Center, New \\ York University School of Medicine, New York, NY \\ i Division of Cardiology, Department of Medicine, Emory University Clinical Cardiovascular \\ Research Institute, Emory University School of Medicine, Atlanta, GA
}

Received May 15, 2017; accepted May 15, 2017

doi: 10.1007/s12350-017-0926-8

This document from the American Society of Nuclear Cardiology represents an updated consensus statement on the evidence base of stress myocardial perfusion imaging (MPI), emphasizing new developments in single-photon emission tomography (SPECT) and positron emission tomography (PET) in the clinical evaluation of women presenting with symptoms of stable ischemic heart disease (SIHD). The clinical evaluation of symptomatic women is challenging due to their varying clinical presentation, clinical risk factor burden, high degree of comorbidity, and increased risk of major ischemic heart disease events. Evidence is substantial that both SPECT and PET MPI effectively risk stratify women with SIHD. The addition of coronary flow reserve (CFR) with PET improves risk detection, including for women with nonobstructive coronary artery disease and coronary microvascular dysfunction. With the advent of PET with computed tomography (CT), multiparametric imaging approaches may enable integration of MPI and CFR with CT visualization of anatomical atherosclerotic plaque to uniquely identify at-risk women. Radiation dose-reduction strategies, including the use of

Electronic supplementary material The online version of this article (doi:10.1007/s12350-017-0926-8) contains supplementary material, which is available to authorized users.

The authors of this article have provided a PowerPoint file, available for download at SpringerLink, which summarizes the contents of the paper and is free for re-use at meetings and presentations. Search for the article DOI on SpringerLink.com.
Reprint requests: Viviany R. Taqueti, MD, MPH, Departments of Medicine and Radiology, Noninvasive Cardiovascular Imaging Program, Brigham and Women's Hospital, ASBI-L1 037-G, 75 Francis Street, Boston, MA 02115; vtaqueti@bwh.harvard.edu J Nucl Cardiol 2017;24:1402-26. 1071-3581/ $\$ 34.00$

Copyright (c) 2017 American Society of Nuclear Cardiology. 
ultra-low-dose protocols involving stress-only imaging, solid-state detector SPECT, and PET, should be uniformly applied whenever possible to all women undergoing MPI. Appropriate candidate selection for stress MPI and for post-MPI indications for guideline-directed medical therapy and/or invasive coronary angiography are discussed in this statement. The critical need for randomized and comparative trial data in female patients is also emphasized.

\section{Key Words: Stable ischemic heart disease • imaging • women • ASNC consensus statement}

\begin{tabular}{|ll|}
\hline Abbreviations & \\
ASNC & American Society of Nuclear \\
& Cardiology \\
AUC & Appropriate use criteria \\
CAC & Coronary artery calcium \\
CAD & Coronary artery disease \\
CVD & Cardiovascular disease \\
CFR & Coronary flow reserve \\
CMD & Coronary microvascular dysfunction \\
CT & Computed tomography \\
ETT & Exercise treadmill testing \\
GDMT & Guideline-directed medical therapy \\
LVEF & Left ventricular ejection fraction \\
MPI & Myocardial perfusion imaging \\
PET & Positron emission tomography \\
SIHD & Stable ischemic heart disease \\
SPECT & Single-photon emission tomography \\
\hline
\end{tabular}

\section{INTRODUCTION}

The evidence base regarding sex differences in cardiovascular imaging is substantial with several recent reviews on the subject. ${ }^{1-6}$ This consensus statement from the American Society of Nuclear Cardiology (ASNC) seeks to provide a comprehensive update to the evidence regarding the utility of nuclear cardiology to evaluate women presenting with symptoms consistent with stable ischemic heart disease (SIHD). ${ }^{7}$ The term SIHD refers to stable patients with suspected or documented myocardial ischemia. This may occur in the presence or absence of obstructive coronary artery disease (CAD), typically defined as luminal narrowing of $70 \%$ or greater in the epicardial vessels. Ischemic heart disease events include sudden cardiac death and acute coronary syndromes, including unstable angina leading to emergent or urgent coronary revascularization. This document supersedes a prior ASNC statement on the value of stress myocardial perfusion imaging (MPI) in women ${ }^{8}$ and aims to represent the use of imaging within the evaluation for SIHD, including testing among those with nonobstructive and obstructive CAD. The current statement highlights the specific evidence supporting the widespread use of MPI single- photon emission tomography (SPECT), and the growing data supporting expanded use of MPI positron emission tomography (PET) in the evaluation of symptomatic women for SIHD. Several prior clinical practice guidelines and consensus statements have been published on this topic. ${ }^{5,7}$

Appropriate delineation and utilization of guidelinedirected care for women with SIHD remain a vital goal. ${ }^{7,9}$ In the last three decades, the case fatality rates for cardiovascular disease (CVD) have been substantially higher for women compared to men. ${ }^{10}$ Part of the excess mortality in women has been related to undertesting and under-treatment of at-risk females. ${ }^{11,12}$ With increased awareness and a focus on guideline-directed strategies for care, there have been recent decreases in CVD mortality; yet these declines have been far less for women than men. ${ }^{13}$ The lack of progress bettering the lives of at-risk women is disappointing and suggests opportunities for an enhanced diagnostic strategy of care that may improve detection and clinical outcomes for female patients with SIHD. The current document reviews the latest evidence on the role of nuclear cardiology techniques in the diagnostic and prognostic evaluation of women. The following topics are included for discussion: (a) appropriate use of MPI in women; (b) MPI with SPECT and PET; (c) MPI as gatekeeper to quality testing patterns in women, including strategies for radiation dose reduction; (d) recent randomized trial evidence of MPI versus other approaches for the evaluation of suspected SIHD; and (e) future directions in clinical research for assessing SIHD in women with and without obstructive CAD.

\section{APPROPRIATE USE OF MPI IN WOMEN}

The role of any imaging procedure, in women or men, is to provide information that refines the clinician's decision-making process with the goal of improving patient symptoms and bettering clinical outcomes. As such, clinical interpretation of radionuclide MPI studies relies upon sequential analysis of disease probability, where the post-test probability is influenced not only by the sensitivity and specificity of the test, but also by the pretest probability of disease. In the setting of chest pain or ischemic equivalent symptoms, the prevalence or 
pretest probability of CAD varies depending on patient characteristics including not only sex, but also age, coronary risk factors, and the nature of presenting symptoms. Patients with low pretest probabilities of CAD are unlikely to benefit from the addition of stress imaging for the purposes of CAD diagnosis or risk stratification, ${ }^{14}$ regardless of the imaging modality used (Table 1). ${ }^{9}$ In patients with a high pretest risk, the addition of stress imaging may improve cardiovascular risk assessment and better guide clinical management including, possibly, coronary revascularization. Thus, an initial strategy of exercise treadmill testing (ETT) without imaging is appropriate for low-intermediate risk women who can exercise and have a normal resting electrocardiogram (ECG), as supported by randomized clinical trial evidence ${ }^{15}$ and recently emphasized in a consensus statement from the American Heart Association (AHA) on the role of noninvasive testing in the evaluation of women with SIHD (Figure 1). ${ }^{5}$ Directing utilization of MPI to those women (and men) generally meeting appropriate indications for testing, as recently summarized in the appropriate use criteria (AUC) of the American College of Cardiology (ACC) ${ }^{9}$ or in the Appropriateness Criteria of the American College of Radiology, ${ }^{16}$ has the added benefits of reducing: (1) unnecessary and potentially harmful downstream procedures, (2) radiation exposure, and (3) cost to the healthcare system; basic tenets of the Institute for Healthcare Improvement's Triple Aim. ${ }^{17}$ Table 1 summarizes the multimodality AUC for the detection and risk assessment of SIHD in symptomatic patients. A core component of quality-based imaging, to balance potential risk with benefit, is the appropriate selection of patients for MPI. For women where testing is not supported by AUC or clinical practice guidelines, the benefit of MPI relative to risk is considered too low, and either a no testing or an alternative test strategy should be considered.

\section{SPECT MPI IN WOMEN FOR EVALUATION OF SIHD}

SPECT MPI is a mature technique that is widely used for the evaluation of suspected or known CAD. In women, SPECT MPI is highly accurate to diagnose flow-limiting (i.e., obstructive) CAD and to stratify risk of IHD events. Advancements in SPECT technology with high count rate imaging, low radiation doses, and theoretically, the potential to quantify myocardial blood flow, ${ }^{18}$ are likely to further advance the utility of SPECT MPI in women.

\section{Diagnostic Accuracy of SPECT MPI in Women}

For patients with intermediate pretest SIHD risk, noninvasive imaging has a well-established role in the diagnosis of CAD. ${ }^{9}$ Radionuclide MPI with SPECT using either exercise or pharmacologic stress testing remains the most common form of stress imaging in the evaluation of patients with known or suspected CAD, and represents a robust approach for diagnosing flow-limiting CAD. A 2012 report from the Agency for Healthcare Research and Quality ${ }^{19}$ addressed the diagnostic accuracy of noninvasive testing techniques as compared with coronary angiography specifically in symptomatic women with

Table 1. Multimodality appropriate use criteria for the detection and risk assessment of ischemic heart disease in symptomatic women and men. Reproduced with permission ${ }^{9}$

\begin{tabular}{|c|c|c|c|c|c|c|c|c|}
\hline \multicolumn{2}{|c|}{ Indication Text } & $\begin{array}{c}\text { Exercise } \\
\text { ECG }\end{array}$ & $\begin{array}{c}\text { Stress } \\
\text { RNI }\end{array}$ & $\begin{array}{c}\text { Stress } \\
\text { Echo }\end{array}$ & $\begin{array}{c}\text { Stress } \\
\text { CMR }\end{array}$ & $\begin{array}{l}\text { Calcium } \\
\text { Scoring }\end{array}$ & ССТА & $\begin{array}{c}\text { Invasive } \\
\text { Coronary } \\
\text { Angiography }\end{array}$ \\
\hline 1. & $\begin{array}{l}\text { - Low pre-test probability of CAD } \\
\text { - ECG interpretable AND able to exercise }\end{array}$ & A & $\mathrm{R}$ & $M$ & $\mathbf{R}$ & $\mathbf{R}$ & $\mathbf{R}$ & $R$ \\
\hline 2. & $\begin{array}{l}\text { - Low pre-test probability of CAD } \\
\text { - ECG uninterpretable OR unable to exercise }\end{array}$ & & A & A & $M$ & $\mathbf{R}$ & $M$ & $\mathrm{R}$ \\
\hline 3. & $\begin{array}{l}\text { - Intermediate pre-test probability of CAD } \\
\text { - ECG interpretable AND able to exercise }\end{array}$ & A & A & A & $M$ & $\mathbf{R}$ & $M$ & $R$ \\
\hline 4. & $\begin{array}{l}\text { - Intermediate pre-test probability of CAD } \\
\text { - ECG uninterpretable OR unable to exercise }\end{array}$ & & A & A & A & $\mathbf{R}$ & A & $M$ \\
\hline 5. & $\begin{array}{l}\text { - High pre-test probability of CAD } \\
\text { ECG interpretable AND able to exercise }\end{array}$ & $M$ & A & A & A & $\mathbf{R}$ & $M$ & A \\
\hline 6. & $\begin{array}{l}\text { - High pre-test probability of CAD } \\
\text { - ECG uninterpretable OR unable to exercise }\end{array}$ & & A & A & A & $\mathbf{R}$ & $M$ & A \\
\hline
\end{tabular}

Appropriate use key: A, Appropriate; $M$, May be appropriate; $R$, Rarely appropriate; CAD, Coronary artery disease; CCTA, coronary computed tomography angiography; $C M R$, cardiac magnetic resonance; ECG, electrocardiography; Echo, echocardiography; $R N I$, radionuclide imaging 


\section{Symptomatic Women with Suspected IHD}

\section{Index IHD Risk Estimate}

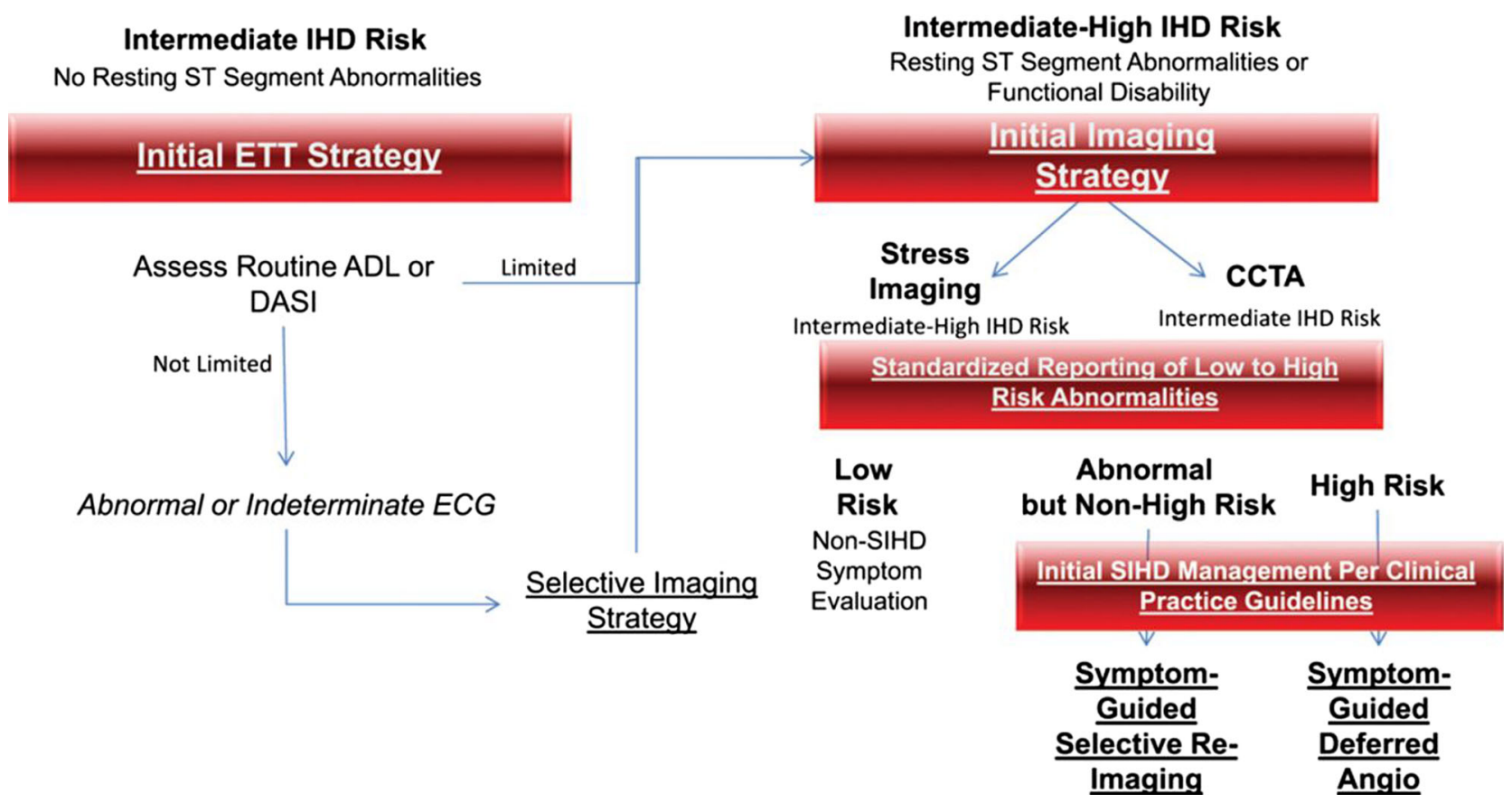

Figure 1. Diagnostic evaluation algorithm for women presenting with SIHD, from the 2014 consensus statement from the American Heart Association. ADL, activities of daily living; Angio, angiography; DASI, Duke Activity Status Index. Reproduced with permission. ${ }^{5}$

suspected SIHD. In a subgroup analysis of 14 studies of 1,000 women with no known CAD, the diagnostic sensitivity was $81 \%$ and specificity was $78 \%$ for detecting obstructive CAD. ${ }^{19}$ In a subsequent analysis of 30 studies evaluating women with known or suspected CAD, SPECT MPI had a sensitivity of $82 \%$ and specificity of $81 \%$ for detecting obstructive CAD. ${ }^{20}$

A strength of SPECT is the availability of robust software programs for the interpretation of MPI. Women have a smaller heart size compared to men, with resultant higher image blurring and, potentially, a lower sensitivity to detect obstructive CAD. Women also have higher left ventricular ejection fraction $(\mathrm{LVEF}),{ }^{21}$ and may have higher normal limits of transient ischemic dilation (TID) ratio compared to men. ${ }^{22}$ As such, sexbased normal limits should be used for reporting of LVEF and volumes. Using sex-based normal limits and software interpretation, diagnostic accuracy for detection of obstructive CAD was high without significant sex differences in a multicenter study of SPECT MPI. ${ }^{23}$
Attenuation correction represents an important consideration to improve the specificity and normalcy rates of SPECT MPI, particularly in women with high likelihood of attenuation from breast tissue and/or high body mass indices (BMI). Correction for attenuation can be achieved through a combination of (1) supine and prone imaging, (2) supine and upright imaging, or (3) direct correction using either line sources or computed tomography (CT). Typically, overall sensitivity does not increase with attenuation-corrected SPECT MPI. ${ }^{24-28}$ In a study of combined supine and prone imaging in normal, overweight, and obese women, Berman et al. ${ }^{29}$ showed that specificity and normalcy rates were unaffected by BMI, whereas sensitivity declined in overweight and obese women compared to normal weight women. In a subsequent study of 459 women evaluated with a quantitative method, Slomka et al. ${ }^{30}$ reported improved specificity and normalcy with no loss in sensitivity when combined supine and prone imaging was performed using a standard Anger camera. Ben- 
Haim et al. ${ }^{31}$ showed that addition of an upright acquisition to the standard supine acquisition using a solid-state cadmium zinc telluride (CZT) camera reclassified $69 \%$ of equivocal scans in males and $77 \%$ of equivocal scans in females as either normal or abnormal. Furthermore, the perceived need for rest scanning in women was reduced by more than $50 \%$. Direct correction for bodily attenuation is possible using either line sources or CT. Attenuation correction has been shown to result in gender-independent distributions of tracer over the entire myocardium, ${ }^{32}$ to improve interpretive certainty, and to reduce the need for rest images when the stress study is acquired first. ${ }^{33}$ Collectively, these techniques have been proven to be of value, and none require additional dosages of radionuclide. As such, this consensus statement encourages consideration of one of these approaches during SPECT MPI, particularly when imaging is performed in women with large breasts, breast implants, and/or high BMIs.

In addition, unique sex differences in the development of atherosclerosis and obstructive CAD may underlie some observed differences in test performance between women and men. There is an increasing recognition that coronary microvascular dysfunction (CMD) with or without epicardial CAD is prevalent in women. $^{34,35}$ In this setting, SPECT MPI may have lower apparent specificity for women as compared to men, especially when obstructive epicardial CAD is used as the reference standard for diagnostic accuracy of MPI.

Exercise versus Pharmacological Stress Testing in Women. Exercise stress is preferred over pharmacological stress for SPECT MPI in women, except among individuals with left bundle branch block (LBBB) or ventricular pacing, or in those incapable of performing adequate exercise, in whom vasodilator stress is preferred. ${ }^{36}$ Exercise stress is physiologic and provides clinical, hemodynamic, and ECG data, which enable important diagnostic and prognostic information. However, among women, exercise-induced ST depression in the absence of CAD has been described in relation to changes in estrogen levels during the menstrual cycle $^{37}$ or from menopausal hormone therapy ${ }^{38}$ and has been associated with lower diagnostic accuracy when compared to men. ${ }^{39}$ In a study of 2,994 asymptomatic women, measures of reduced functional capacity (low exercise capacity, low heart-rate recovery, and not achieving target heart rate) rather than ischemic ST depression provided prognostic value. ${ }^{40}$ As discussed later, results of the multicenter randomized WOMEN (What is the Optimal Method of Ischemia Elucidation in WomeN?) trial indicated no advantage of ETT with MPI over ETT alone in low-intermediate risk women able to exercise. ${ }^{15}$ In contrast, in women with intermediate- high pretest SIHD risk, the diagnostic accuracy to detect obstructive CAD is greater for ETT with SPECT MPI than for ETT alone (MPI, sensitivity 78\% [95\% CI 72\% to $83 \%$ ] versus ETT only, sensitivity $61 \%$ [95\% CI $54 \%$ to $68 \%])^{41}$ An alternative strategy includes adding SPECT MPI following an intermediate risk ETT.

Nonetheless, exercise capacity is commonly limited in women referred for SPECT MPI, who are typically older and have significant comorbidities. These patients may need graded exercise stages that increase the metabolic equivalents of work in a more gradual manner than in the commonly used Bruce protocol. In women who are unable to exercise adequately, pharmacological stress testing provides an alternative to exercise stress testing. Among men and women with normal adenosine SPECT MPI, women more frequently manifest ischemic ECG changes. $^{42}$ Despite a normal adenosine SPECT MPI, rates of CAD death and nonfatal myocardial infarction (MI) were higher in women with ischemic ECG changes compared to those without ischemic ECG changes. ${ }^{42,43}$

It is unlikely that differences in the dosing regimen of vasodilators significantly impact test sensitivity of pharmacological stress MPI among female and male patients. Although adenosine and dipyridamole are weight-based infusions and, in general, women receive a smaller absolute dose of adenosine or dipyridamole compared to men, adenosine ${ }^{44}$ and dipyridamole ${ }^{45}$ SPECT are similarly diagnostically accurate in women and men. In addition, although regadenoson is a nonweight-based injection of $400 \mathrm{mcg}$, integrated data from the two-phase 3 ADenoscan Versus regAdenosoN Comparative Evaluation for MPI (ADVANCE MPI) trials, which included $30 \%$ women, demonstrated that regadenoson as compared to adenosine was safe, welltolerated, and similarly effective in women as in men. ${ }^{46}$

Data support that adjustment for pretest likelihood of CAD improves the diagnostic accuracy of SPECT MPI in women, resulting in no significant differences in women compared to men. ${ }^{47}$ In a study using vasodilator stress and technetium-99m $\left({ }^{99 m} \mathrm{Tc}\right)$ MPI, the sensitivity, specificity, and normalcy rates for detection of obstructive CAD were high at $93 \%, 78 \%$, and $88 \%$, respectively; sensitivity and specificity did not vary significantly by pretest likelihood of CAD. But, as in men, test sensitivity in women was lower for detection of significant luminal narrowing in the left circumflex territory relative to the left anterior descending or right coronary territories. ${ }^{44}$ Test performance was high likely due to better image quality with ${ }^{99 \mathrm{~m}} \mathrm{Tc}$ MPI (higher energy photons and gated imaging) as compared to thallium $\left({ }^{201} \mathrm{Tl}\right)$. The value of ${ }^{99 \mathrm{~m}} \mathrm{Tc}$ MPI and gated SPECT is highlighted by data from another study 
wherein the specificity of MPI to exclude obstructive epicardial CAD improved from $67.2 \%$ with ${ }^{201} \mathrm{Tl}$ MPI to $84.4 \%$ with ${ }^{99 \mathrm{~m}} \mathrm{Tc}$ MPI, and to $92.2 \%$ with ${ }^{99 \mathrm{~m}} \mathrm{Tc}$ MPI combined with gated SPECT. ${ }^{48}$ In high-risk women, exercise perfusion variables identified high-risk CAD better than ETT variables alone. ${ }^{49}$

Other studies have reported sex differences in the diagnostic accuracy of SPECT MPI, with lower accuracy for SPECT MPI in women compared to men. ${ }^{50-52}$ As already discussed, this lower diagnostic accuracy among women has been variably attributed to multiple epidemiological, biological, and imaging factors such as imaging of women with a low pretest likelihood of obstructive $\mathrm{CAD}$, reduced exercise capacity and lower maximal heart rates achieved during exercise (women referred for testing are generally older than men), higher prevalence of CMD and single vessel CAD wherein SPECT MPI is known to have a reduced sensitivity, smaller cardiac size, and anterior wall attenuation artifacts from breast tissue.

\section{Risk Stratification of Women with SPECT MPI}

SPECT MPI plays a pivotal role in risk stratification of women with known or suspected CAD. ${ }^{21,53-56}$ In a large meta-analysis, after a mean follow-up of 36 months, the prognostic value of a normal SPECT MPI among women was excellent with 99\% event-free survival, and similar to that of men. ${ }^{57}$ A normal SPECT MPI in the setting of a normal stress ECG portended excellent survival free of future CAD death or MI. ${ }^{58}$ In contrast, the presence of abnormal ST segment changes with a normal MPI was associated with an elevated risk of major adverse cardiac events. Abnormal SPECT MPI provides incremental risk stratification over ETT variables alone. Hachamovitch et al. ${ }^{53}$ showed in a study of 4,136 patients $(33.7 \%$ women) that MPI variables provided incremental prognostic value over ETT variables for women and men followed over a mean of $20 \pm 5$ months. Mild, moderate, or severely abnormal SPECT MPI scans were associated with graded increases in adverse CAD events in women. MPI findings provided better discrimination of risk, identifying higher risk women compared to higher risk men (area under the receiver operating characteristics curve $=0.84 \pm 0.03$ versus $0.71 \pm 0.03, P<0.0005) .{ }^{53}$

In addition to clinical and perfusion variables, left ventricular $(\mathrm{LV})$ volumes and LVEF on SPECT MPI provide incremental prognostic value beyond MPI and clinical variables in predicting CAD death or MI. ${ }^{21,59}$ In a study of 597 women and 824 men, Sharir et al. ${ }^{21}$ demonstrated that normal limits of LVEF vary by sex and determine prognosis (Figure 2). In that study, women with severe ischemia were at very high risk of CAD death or MI if their LVEF was $<51 \%$ (3-year event rate $39.8 \%$ versus $10.8 \%$ for $\mathrm{EF} \geq 51 \%$ ). Parallel results were shown in women for LV end systolic volume index (ESVI) $>27 \mathrm{~mL} / \mathrm{m}^{2}$ (3-year event rate $35.1 \%$ versus $15.2 \%$ for ESV $\leq 27 \mathrm{~mL} / \mathrm{m}^{2}$ ). Although both perfusion and function variables predicted prognosis in women and men, perfusion variables appeared to add substantially more power than function variables to predict adverse events in women. ${ }^{21}$ Finally, other studies have confirmed the excellent prognostic value of SPECT MPI in women, including elderly women ${ }^{60}$ and women of diverse racial and ethnic subsets. ${ }^{61}$

A large body of literature supports the excellent prognostic value of normal stress-only SPECT imaging when attenuation correction is employed. ${ }^{62,63}$ In one pooled analysis (of 22,443 patients, $46.5 \%$ with a stressonly study), a normal stress-only study was associated with an annual cardiac event rate of $0.7 \% .^{58}$ This risk is low and comparable to that associated with a normal rest and stress MPI. The study of Chang et al. ${ }^{62}$ showed that a normal stress-only scan conferred the same low likelihood of events in women as in men.
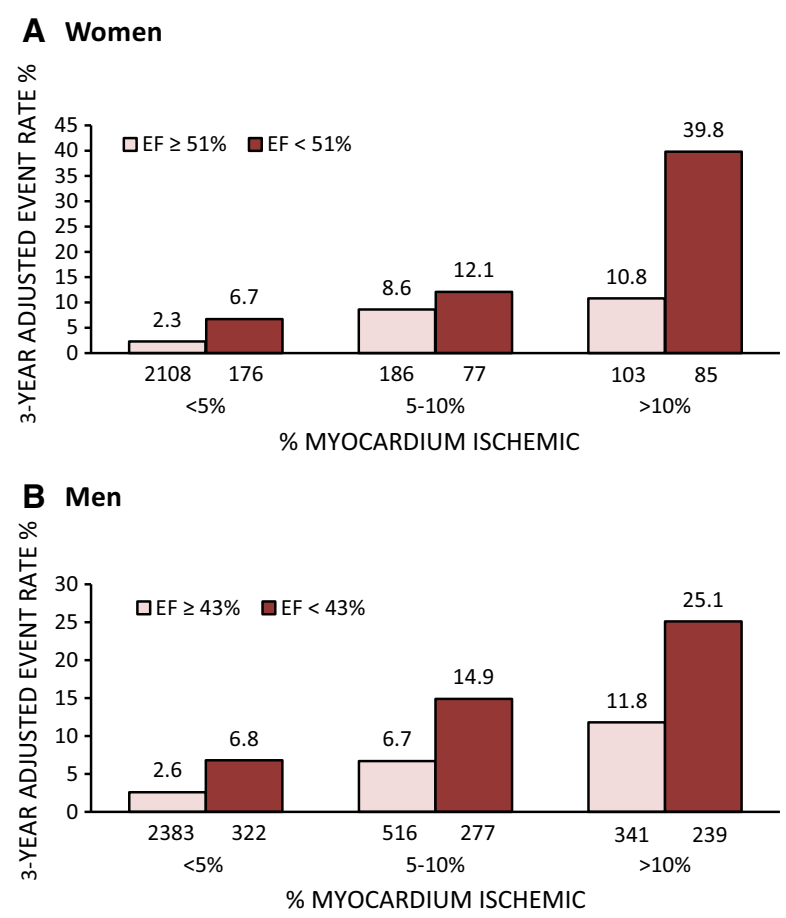

Figure 2. Three-year adjusted rate of cardiac death or myocardial infarction in women $(\mathbf{A})$ and men $(\mathbf{B})$ as a function of ischemia and LVEF. Normal limits of LVEF are $\geq 51 \%$ in women and $\geq 43 \%$ in men. $L V E F$, left ventricular ejection fraction. Adapted with permission. ${ }^{21}$ 


\section{Hybrid SPECT with CT Imaging}

An evolving body of literature supports the utility of SPECT MPI combined with coronary artery calcium (CAC) scoring ${ }^{64-70}$ or coronary CT angiography (CCTA) to assess for the presence of stress-induced myocardial ischemia along with coexistent calcified and noncalcified atherosclerotic plaque. CAC can be visualized not only on a dedicated high dose, breath-hold CT scan, but also on the non-gated low dose CT scan obtained for attenuation correction, although sensitivity for detecting CAC may be reduced in the latter. ${ }^{71}$

Studies incorporating CAC scoring into SPECT imaging highlight three key points. First, a CAC score of 0 is associated with low rates of ischemia among symptomatic individuals (ischemia was noted in $<3 \%$ of individuals with CAC score $<100)^{64,68}$ and in asymptomatic diabetic individuals. ${ }^{67}$ In a recent trial of CAC followed by selective downstream testing only in those with detectable $\mathrm{CAC},{ }^{72}$ downstream testing was reduced by $40 \%$ and no CAD events were observed through one year of follow-up among those with a CAC score of 0 . Other literature, however, suggests that the risk of patients with a CAC of 0 is heterogeneous, and driven by underlying clinical risk. ${ }^{73}$ Second, the frequency of ischemia increases with increasing CAC scores. Among symptomatic patients, $>25 \%$ of individuals with CAC score $\geq 1000$ demonstrated ischemia. ${ }^{68}$ Third, as many as $75 \%$ of individuals with normal MPI may have underlying calcified coronary atherosclerosis. ${ }^{68}$ A high CAC score with normal MPI portends a low risk of short-term events (i.e., within the first 3 years), but a higher risk of events in the intermediate- to long-term (>3 years). ${ }^{64,67,69,70}$ While most of the above studies included a large predominance of men, a recent large study compared the prognostic value of CAC scoring among asymptomatic, low-intermediate risk patients, of whom $45.4 \%$ were women. ${ }^{74}$ In this study, women compared to men were older, had a greater prevalence of $\mathrm{CAC}$, and a higher 15-year mortality. Although the literature on CAC scoring combined with MPI in symptomatic women is limited, these findings support the addition of CAC in women to improve risk stratification beyond traditional algorithms.

Several investigators have evaluated simultaneous or sequential MPI and CCTA to identify the hemodynamic significance of coronary stenoses detected on CTA, particularly for indeterminate stenoses. ${ }^{75-77}$ Stress-only MPI with CTA has also been proposed as a low-radiation dose protocol with comprehensive ischemia and atherosclerosis imaging. ${ }^{78}$ An abnormal SPECT MPI along with abnormal CTA was associated with an annual death rate of $6 \%$, and independently associated with a high risk of death and MI
$(P<0.005){ }^{79}$ However, to date, the results of these studies do not identify any patient subgroup preferentially benefiting from the use of combined MPI and coronary atherosclerosis imaging protocols, and limited data specific to women are available.

\section{Solid-State Detector SPECT MPI}

Novel solid-state detector cardiac SPECT scanners demonstrate vastly improved count performance and superior energy discrimination compared to conventional $\mathrm{NaI}$ detector SPECT scanners. ${ }^{80}$ Solid-state scanners also include advanced reconstruction methods of iterative reconstruction, noise reduction, and resolution recovery that enhance image quality and speed of acquisition, and reduce radiation dose. ${ }^{80}$ Upright imaging (feasible with some scanners) may change patterns of breast attenuation or minimize attenuation artifacts in women. Dynamic tomographic SPECT imaging is feasible with some of these scanners, and under investigation for quantification of myocardial perfusion reserve,${ }^{81}$ which may be useful to identify CMD. Enhancements allowing for high efficiency and improved image quality make solid-state detector SPECT particularly valuable for MPI in women. Although limited literature exists on the diagnostic accuracy of this technology in women or in general, ${ }^{82-84}$ one study showed that the diagnostic accuracy of solidstate ${ }^{99 \mathrm{~m}} \mathrm{Tc}-\mathrm{SPECT}$ is high in women (area under receiver operating characteristic [ROC] curve, 0.822 [95\% CI 0.685 to 0.959 ] and comparable to diagnostic accuracy in men [overall ROC area $0.884,95 \%$ CI 0.836 to 0.933 ]). ${ }^{84}$

\section{SPECT Summary Statement}

Prompt evaluation of anginal symptoms in women is critical to initiate guideline-directed strategies of care aimed at improving IHD outcomes. SPECT MPI is widely available with high diagnostic and prognostic accuracy for women and men. Although ETT alone may suffice in the evaluation of lower risk women with good functional capacity and a normal rest ECG, SPECT MPI is particularly effective for identification of women at high risk of IHD events. Strategies are available to address women-specific attenuation patterns, such as those from large breasts or breast implants. Stress-first (i.e., stress-only when normal) imaging with attenuation correction is as effective in women as in men, and should be preferentially utilized when appropriate. Solid-state detector SPECT technology holds promise to further enhance the utility of SPECT MPI for women with improved throughput, superior image quality, and potentially, the ability to quantify myocardial blood flow for the assessment of diffuse CAD and CMD. 


\section{PET MPI IN WOMEN FOR EVALUATION OF SIHD}

Over the last decade, radionuclide MPI with PET has become a powerful tool for the diagnosis and risk stratification of patients with known or suspected CAD. ${ }^{3,85}$ Here, we describe the maturing role of PET imaging in women, particularly in the evaluation of SIHD. PET imaging offers distinct advantages in the evaluation of myocardial ischemia in women, such as (1) improved diagnostic accuracy, (2) low-radiation exposure using short-lived radiopharmaceuticals, and (3) the ability to quantify myocardial blood flow and coronary flow reserve to diagnose ischemia, even in the absence of obstructive CAD. As such, cardiac PET MPI stands to play a unique role in defining the diagnosis and prognosis of women with SIHD, while also guiding new treatment strategies for their more prevalent cardiovascular disease phenotypes.

\section{Diagnostic Accuracy of PET MPI in Women}

For symptomatic intermediate risk women who are capable of exercising and have an interpretable resting ECG, the ETT remains the recommended initial diagnostic test. ${ }^{5}$ For the sizeable number of patients in whom the addition of imaging is indicated, there are unique characteristics of PET that make it particularly appealing for the evaluation of women. PET MPI has excellent diagnostic performance for the detection of CAD and is now performed in over 200 medical centers in the United States and a growing number of centers worldwide. $^{85}$ Relative to conventional stress testing with SPECT MPI or echocardiographic regional wall motion assessment, PET MPI provides images of high diagnostic quality and improved diagnostic accuracy, with an average sensitivity of $90 \%$ and specificity of $89 \%$ for detecting angiographically significant coronary stenoses. $^{86}$ Recent meta-analyses have confirmed incremental improvement in diagnostic accuracy with PET relative to SPECT for the diagnosis of obstructive $\mathrm{CAD},{ }^{87,88}$ with an area under the ROC curve of 0.95 and 0.90 for PET and SPECT $(P<0.0001)$.

Several technical advantages account for the enhanced diagnostic ability of PET. These include: (1) routine measured (depth-independent) attenuation correction, which decreases false positives and thereby increases specificity; (2) high spatial and contrast resolution (heart-to-background ratio), which allows improved detection of small perfusion defects, thereby decreasing false negatives and increasing sensitivity; (3) the use of short-lived radiopharmaceuticals, which translate into very low-radiation doses as well as fast sequential assessment of rest/stress perfusion imaging, which allows for high laboratory efficiency and patient throughput; and (4) high temporal resolution, which allows for fast dynamic imaging of tracer kinetics and makes possible the absolute quantification of myocardial perfusion (in $\mathrm{mL} / \mathrm{min} / \mathrm{g}$ of tissue). ${ }^{85}$ In women, these advantages may be especially relevant given: (1) the risk of false positives due to attenuation from breast or general adipose tissue in those with high BMI; (2) the risk of false negatives due to partial volume effects, which are amplified in small left ventricles; (3) the need to minimize exposure to radiation, particularly among women of reproductive age; and (4) a high prevalence of nonobstructive $\mathrm{CAD}$ and $\mathrm{CMD}$, which are not benign phenotypes, but instead, increasingly recognized to be associated with significant cardiovascular morbidity and mortality. ${ }^{89,90}$

PET MPI allows for the evaluation of multiple functional risk markers, ${ }^{85}$ including regional perfusion defect size and severity, LVEF, TID of the left ventricle, right ventricular tracer uptake, lung uptake, stress and rest myocardial blood flow, and their ratio coronary flow reserve, CFR. Selective incorporation of CT into hybrid or sequential PET/CT imaging protocols, either with quantification of CAC scoring or with CCTA, adds the ability to evaluate for anatomical disease, thereby increasing test sensitivity for diagnosis of CAD, including nonobstructive plaque (Figure 3 ). ${ }^{3}$

\section{Risk Stratification of Women with PET MPI}

There are now extensive data from observational studies supporting not only the diagnostic, but also the prognostic value of PET MPI in women and men with known or suspected CAD. The cumulative evidence in more than 7,000 patients ( $>47 \%$ women), including from the rubidium-82 $\left({ }^{82} \mathrm{Rb}\right)$ PET Prognosis Multicenter Registry, indicates that a normal scan is associated with excellent prognosis, and that the magnitude of stress and rest perfusion defects on PET MPI provides valuable risk stratification of patients undergoing pharmacologic stress testing. ${ }^{91-96}$ Specifically, a normal scan indicated low risk $(<1 \%$ annual cardiac event rate) while an abnormal scan indicated worsening prognosis $(>4.2 \%$ annual event rate). There was a graded increase in risk of CAD events with more extensive and severe perfusion defects (predicted CAD death increased by one-third for every $10 \%$ increase in percent myocardium ischemia, and by more than one-half for every $10 \%$ increase in percent myocardium scar); meaningful risk reclassification for CAD death occurred for 1 in 9 patients. ${ }^{91}$ A sexspecific analysis of the PET Prognosis Multicenter Registry yielded similar results. ${ }^{97}$ Although there were significant differences in clinical characteristics (i.e., women as compared to men had lower frequency of prior CAD, higher frequency of normal scans, and 


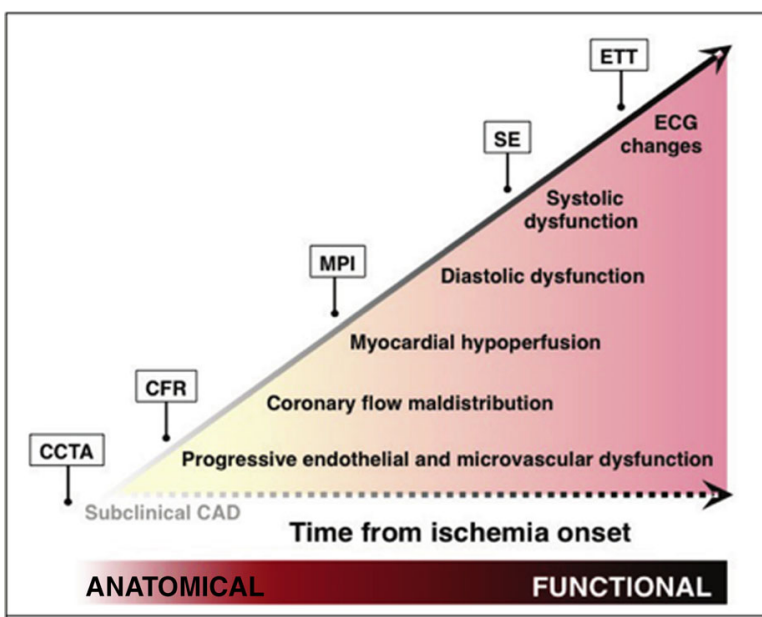

Figure 3. Schematic of the ischemic cascade, a sequence of pathophysiologic events associated with CAD, and multimodality cardiovascular imaging approaches for the evaluation of patients with known or suspected CAD. Anatomy-based and quantitative functional imaging probes earlier events in the cascade than does traditional MPI. This may be especially relevant for the evaluation of women. CCTA, coronary computed tomography angiography; $C F R$, coronary flow reserve; $M P I$, myocardial perfusion imaging; $S E$, stress echocardiography; ETT, exercise treadmill testing. Adapted with permission. ${ }^{3}$

experienced lower rates of cardiac mortality), the percentage of abnormal stress myocardium was independently predictive of CAD mortality such that the prognostic value of PET MPI was similar in women and men (Figure 4A). ${ }^{97}$ The integration of perfusion and function, enabled by the assessment of LVEF and volumes with PET MPI, adds important prognostic information that was found to be similar in women and men (e.g., LVEF is inversely related to CAD mortality, Figure 4B) ${ }^{97}$ Further, the possibility of assessing the change in LVEF from baseline to peak vasodilator stress (especially with the use of a short half-life tracer such as ${ }^{82} \mathrm{Rb}$ for PET MPI) may also provide useful diagnostic and prognostic data. ${ }^{98}$

\section{Quantification of Coronary Blood Flow and Reserve}

An area where PET holds great promise to contribute differentially to the evaluation of women with symptoms of myocardial ischemia is in the quantification of myocardial blood flow and reserve. Growing data support that the pathophysiology of CAD in women may vary as compared to men. ${ }^{35,89,90,99,100}$ Although women frequently have less anatomical obstructive $\mathrm{CAD}$, this does not necessarily translate into fewer IHD events. ${ }^{101}$ A major contributor to this apparent paradox may be vascular dysfunction in the form of abnormal coronary reactivity due to diffuse endothelial dysfunction and plaque erosion. ${ }^{34,102}$ Thus, testing for SIHD, especially in women, needs to progress beyond testing for the presence or absence of obstructive epicardial CAD. This is where PET MPI with quantification of CFR may play an important role. Coronary flow reserve (calculated as the ratio of hyperemic to rest absolute myocardial blood flow) is an integrated marker of coronary vasomotor dysfunction that measures the hemodynamic effects of focal, diffuse, and small-vessel coronary artery disease on myocardial tissue perfusion, ${ }^{103}$ and is emerging as an important noninvasive prognostic imaging marker of cardiovascular risk. Recent data have consistently shown that CFR measurements by PET can distinguish patients at low or high risk for serious adverse events, including cardiac death, ${ }^{104-107}$ beyond comprehensive clinical assessment, LVEF, or traditional semi-quantitative measures of stress-induced ischemia. ${ }^{104,105} \mathrm{~A}$ preserved CFR effectively excluded high-risk angiographic CAD with a sensitivity of $86 \%$ and a negative predictive value of $97 \%$ in patients with normal or mildly to moderately abnormal $(<10 \% \mathrm{LV}$ ischemia and/or scar) PET MPI. ${ }^{108}$ Conversely, an impaired CFR of $<2$ has been associated with a 3.4-fold increased hazard of CAD death, and a severely impaired CFR 1.5 has been associated with a 5.6-fold increased risk of CAD death. ${ }^{104}$ This continuum of cardiovascular risk is illustrated in Figure 5. ${ }^{109}$ While a CFR value of $\geq 2$ was associated with relatively low rates of annualized cardiac death, the event rate for patients with CFR values of $<2$ increased exponentially as CFR decreased. ${ }^{109,110}$ Thus, patients who doubled (or more) their resting coronary blood flow during stress conditions demonstrated a relatively good prognosis. For patients with CFR $<2$, prognosis may be substantially worse, but not necessarily in a manner directly attributable to obstructive CAD. As CFR is a measure of not only the effects of epicardial CAD, but also of diffuse atherosclerosis and microvascular dysfunction on myocardial tissue perfusion, worse prognosis in patients with CFR $<2$ may be associated with coronary vasomotor dysfunction arising from a mix of pathophysiologic CAD phenotypes. Indeed, impaired global CFR is associated with major cardiovascular events independently of coronary angiographic severity (Figure 6), and modifies the effect of coronary revascularization. ${ }^{111}$

This may have important implications for women with SIHD. There is emerging evidence that patients, particularly women, with very low CFR may be at an especially elevated risk of cardiovascular events. In a clinical cohort of symptomatic patients referred for invasive coronary angiography after PET MPI, women 

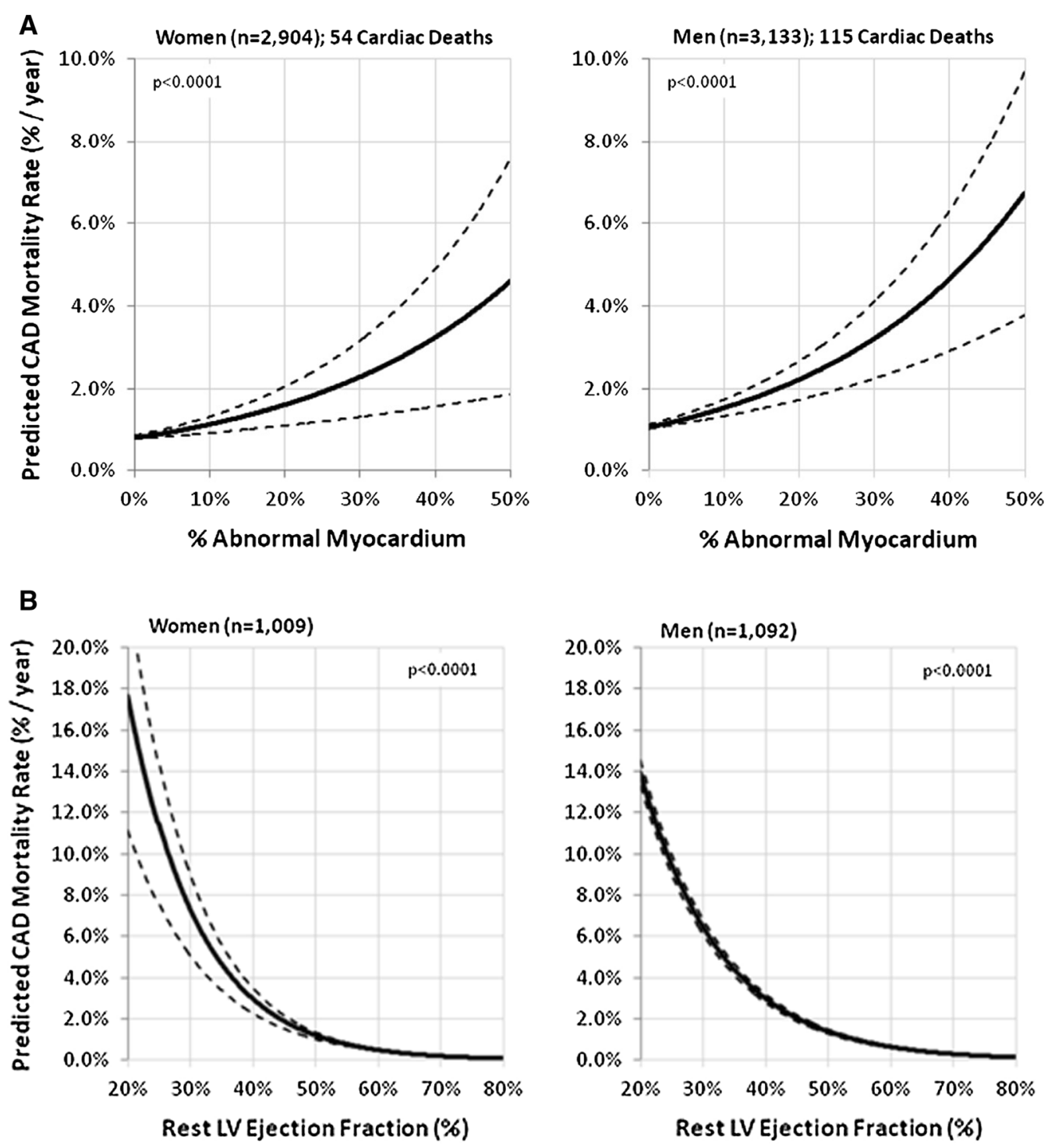

Figure 4. Plots of the predicted CAD mortality per year (and $95 \%$ confidence intervals) by the percentage of abnormal myocardial perfusion at stress (A) and by the rest LVEF $(\mathbf{B})$ on ${ }^{82} \mathrm{Rb}$ PET imaging in women and men. An exponential trendline was used to plot CAD mortality for women and men. Reproduced with permission. ${ }^{97}$

had a significantly lower burden of obstructive CAD relative to men, but were not protected from cardiovascular events, ${ }^{35}$ consistent with the previously described epidemiologic trends. ${ }^{12,113}$ However, by further exploring the contribution of PET-quantified CFR in this cohort, Taqueti et al. ${ }^{35}$ arrived at new insights regarding the interplay of sex, anatomical CAD severity, and coronary vasomotor dysfunction on adverse events. While most men with severely impaired CFR were found to have $\geq 1$ vessel CAD on coronary angiography, most women with similarly impaired CFR demonstrated $\leq 1$ vessel CAD. Yet, despite a lower pretest probability of CAD and a lower burden of diagnosed angiographic $\mathrm{CAD}$, women experienced a greater risk of cardiovascular events as compared to men. In adjusted analysis, as much as $40 \%$ of this observed "sex gap", or differential effect of sex on outcomes, was mediated by CFR. ${ }^{35}$ This implies that a very low CFR $(<1.6)$ may be a critical link to understanding the hidden biological risk of IHD among women. Previous data from the same group support that revascularization, especially by coronary artery bypass surgery $(\mathrm{CABG})$, in certain individuals with severely impaired CFR may be beneficial. ${ }^{111}$ That sex differences on outcomes of cardiovascular events are 


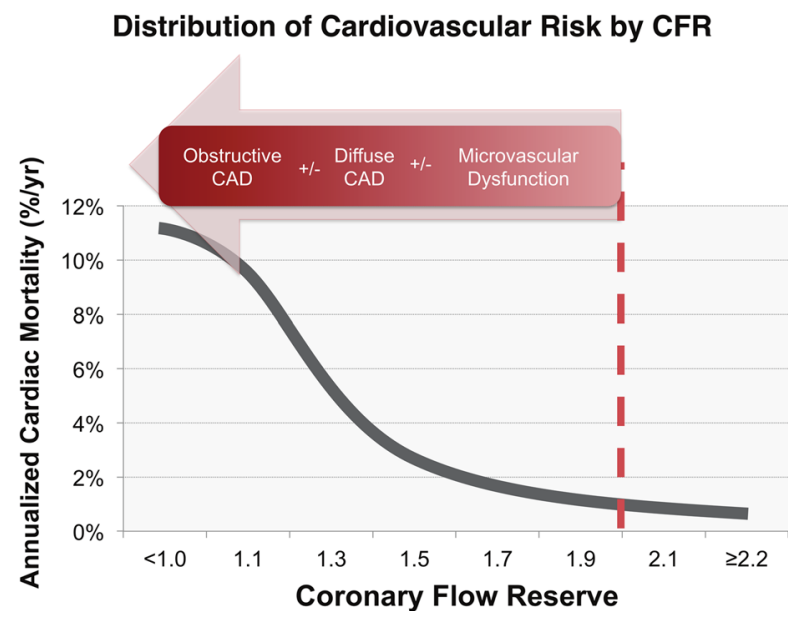

Figure 5. Distribution of cardiovascular risk by PET MPI coronary flow reserve (CFR). A CFR value of $\geq 2$ is associated with relatively low rates of annualized cardiac death. Conversely, CFR values $<2$ are associated with substantially worse prognosis, which may result from vasomotor dysfunction arising from a combination of pathophysiologic CAD phenotypes, including multivessel obstructive CAD, diffuse atherosclerosis, and coronary microvascular dysfunction. Reproduced with permission. ${ }^{109}$

amplified in those with severely impaired CFR (Figure 7$)^{35}$ further suggests that certain patients (e.g., with very low CFR and less obstructive CAD, a phenotype more prevalent in women) may be at especially high risk. Thus, while providing optimal, equitable guidelinedirected medical care remains a critical goal for managing women with SIHD,, 112 additional research is needed to determine precisely what that might be for this subset of vulnerable patients with a predominance of women.

These findings collectively highlight the morbidity associated with diffuse atherosclerosis and CMD. Indeed, even in the setting of normal PET MPI (e.g., no flow-limiting CAD), impaired CFR adds important prognostic value. In a lower risk cohort of symptomatic patients with normal semi-quantitative MPI by PET and less severely reduced CFR, CFR but not sex was independently associated with major adverse cardiovascular events. ${ }^{114}$ That is, both women and men with CMD (CFR $<2$ in the presence of normal MPI) experienced worse outcomes, although this phenotype was twice as prevalent in women as in men. This result was consistent even in patients with a CAC score of $0,{ }^{114}$ and global CFR, but not CAC, provided significant incremental risk stratification over clinical risk score for prediction of major adverse CAD events. ${ }^{115}$ Thus, symptomatic patients who do not demonstrate ischemia associated with flow-limiting CAD may have diffuse atherosclerosis and CMD for which a more sensitive, quantitative assessment of ischemia may better diagnose abnormalities and identify novel targets for systemic therapies. Although this is not a uniquely female disorder, this pattern of abnormalities may be especially relevant in certain subsets of women, including those with diabetes and/or metabolic syndrome, low-detectable levels of cardiac troponin, ${ }^{116}$ heart failure with preserved LVEF (HFpEF), ${ }^{117}$ atrial fibrillation, and those following chemotherapy and radiation from breast cancer or Hodgkin's lymphoma, respectively.

\section{Novel Cardiac PET Applications}

Finally, the clinical indications for cardiac PET imaging in women extend beyond coronary blood flow to molecular and cellular events in the myocardium. Examples of this include the use of fluorine-18 $\left({ }^{18} \mathrm{~F}\right)$ fluorodeoxyglucose (FDG) PET in the evaluation of hibernating myocardium in patients with ischemic cardiomyopathy, ${ }^{118}$ and in the evaluation of inflammatory infiltrate in patients with suspected or known cardiac sarcoidosis. ${ }^{119}$

\section{PET Summary Statement}

Quantitative PET holds the potential to elucidate the distinct pathophysiology of IHD in women, while also improving diagnostic accuracy and reducing patient exposure to radiation relative to traditional approaches. As such, PET MPI represents a significant contribution to the patientcentered evaluation of myocardial ischemia across the various $\mathrm{CAD}$ phenotypes prevalent in both women and men.

\section{MPI AS GATEKEEPER TO QUALITY TESTING PATTERNS IN WOMEN: FOCUS ON TEST EFFICIENCY, COST EFFECTIVENESS, AND RADIATION DOSE REDUCTION}

A core component of appropriate identification of patients and the ensuing test-driven strategies must include consideration of costs associated with the diagnostic episode of care. Critical cost issues for cardiovascular imaging include layered or sequential testing patterns as well as the cost consequences of comparative testing patterns over both the near- and long-term duration of care. ${ }^{120}$ The appropriate selection of patients can markedly reduce the need for additional testing, largely through eliminating testing for those with rarely appropriate indications. ${ }^{121}$

\section{Test Efficiency and Cost Effectiveness of MPI in Women}

Few studies examine the cost efficiency or cost effectiveness of MPI, with even less focusing on 

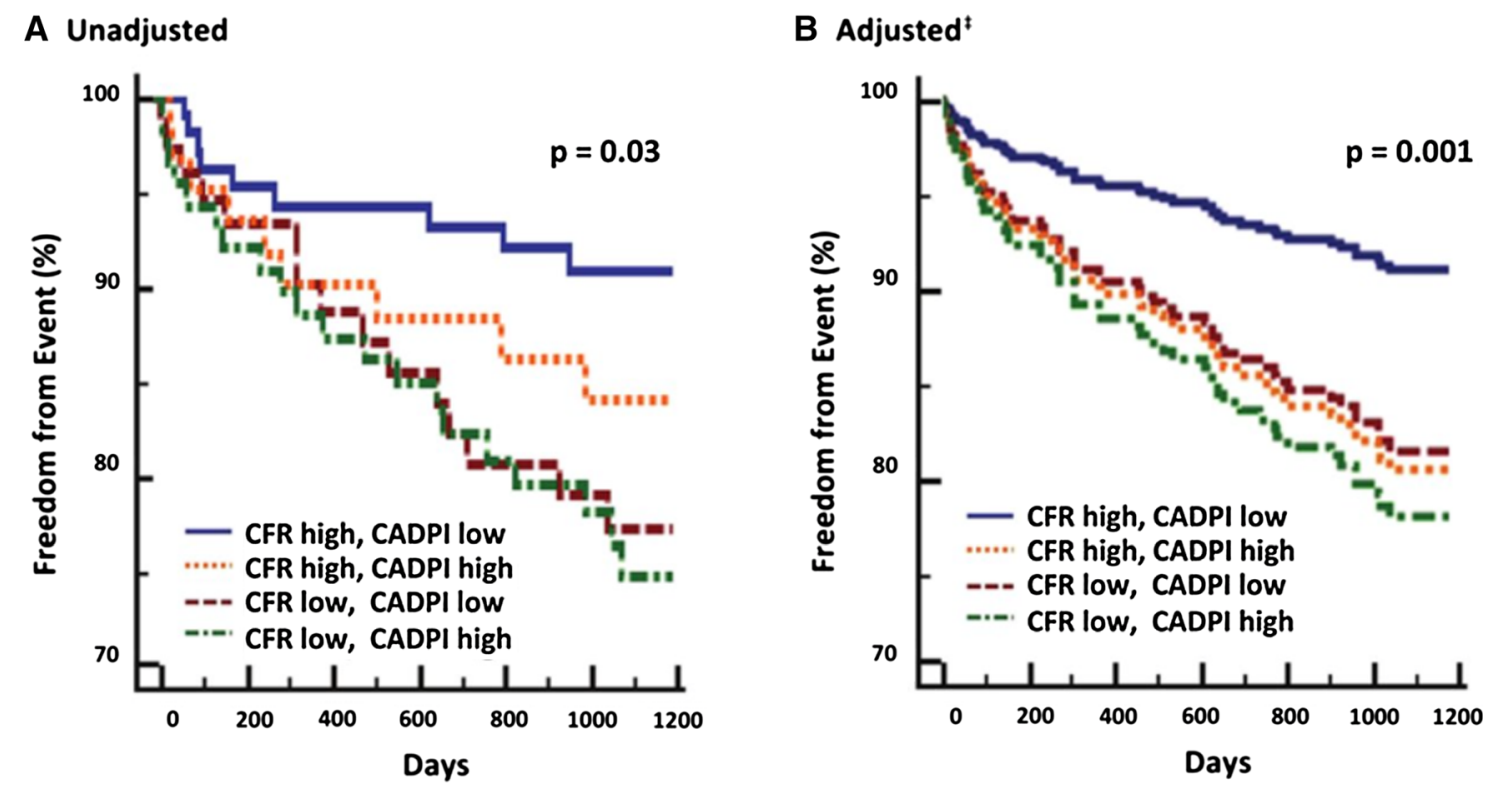

\begin{tabular}{lccc}
\hline & Total $(\mathbf{N}=\mathbf{3 2 9})$ & Early Revascularization (\%) & by PCI (\%) \\
\hline CFR high, CADPI low & 106 & $38(35.8)$ & $34(89.5)$ \\
CFR high, CADPI high & 60 & $49(81.7)$ & $36(73.5)$ \\
CFR low, CADPI low & 74 & $35(47.3)$ & $34(97.1)$ \\
CFR low, CADPI high & 89 & $71(79.8)$ & $50(70.4)$ \\
\hline
\end{tabular}

Figure 6. Freedom from cardiovascular death or heart failure admission according to PET MPI coronary flow reserve (CFR) and invasive luminal angiographic score (CAD prognostic index, CADPI). A Patients with very low CFR $(<1.6)$, independently of angiographic disease score, experienced higher rates of events. B In adjusted analysis, patients with very low CFR experienced rates of events similar to those of patients with very high CADPI $(>37)$. PCI percutaneous coronary intervention. CFR denotes coronary flow reserve: high $(\geq 1.6)$, low $(<1.6)$. CADPI denotes coronary artery disease prognostic index: low $(<3.7)$, high $(\geq 37$, reflects $>70 \%$ stenosis in $>1$ epicardial artery). ${ }^{\ddagger}$ Adjusted for pretest clinical score, left ventricular ischemia, and early revascularization with percutaneous coronary intervention (PCI) or coronary artery bypass grafting $(\mathrm{CABG})$. Early revascularization denotes that within 90 days of noninvasive imaging. Reproduced with permission. $^{111}$

women. A large observational study of 11,372 patients with stable angina revealed that a selective ischemiadriven approach using SPECT MPI prior to invasive coronary angiography provided substantial cost savings without significant differences in clinical outcomes compared to a strategy of direct invasive coronary angiography. ${ }^{122}$ A subanalysis of 4,638 women from this study demonstrated that MPI followed by selective angiography minimized near-term costs compared to direct invasive coronary angiography regardless of pretest likelihood of CAD. ${ }^{123} \mathrm{~A}$ similar analysis was reported and projected additional cost savings associated with PET MPI compared with SPECT MPI. ${ }^{124}$ In another observational registry of 9,521 symptomatic women, exercise SPECT MPI provided incremental cost effectiveness compared to echocardiography among women with established $\mathrm{CAD}$, or women at high risk of CAD events ( $\geq 2 \%$ annual risk). ${ }^{125}$

The WOMEN trial evaluated the cost efficiency of exercise SPECT MPI versus ETT in women with low to intermediate risk. ${ }^{15}$ In this randomized trial, 824 symptomatic women with low-intermediate pretest likelihood of IHD and a Duke Activity Status Index of $\geq 5$ metabolic equivalents (METS) were randomized to a strategy of ETT alone or ETT with SPECT MPI. An initial diagnostic strategy of ETT alone resulted in a similar 2-year outcome of major adverse CAD events (CAD death, hospitalization for an acute coronary syndrome, or heart failure), and $48 \%$ diagnostic cost savings $(P<0.001)$ compared to exercise MPI. ${ }^{15}$

In a related example, the National Heart, Lung, and Blood Institute (NHLBI)-sponsored Prospective 


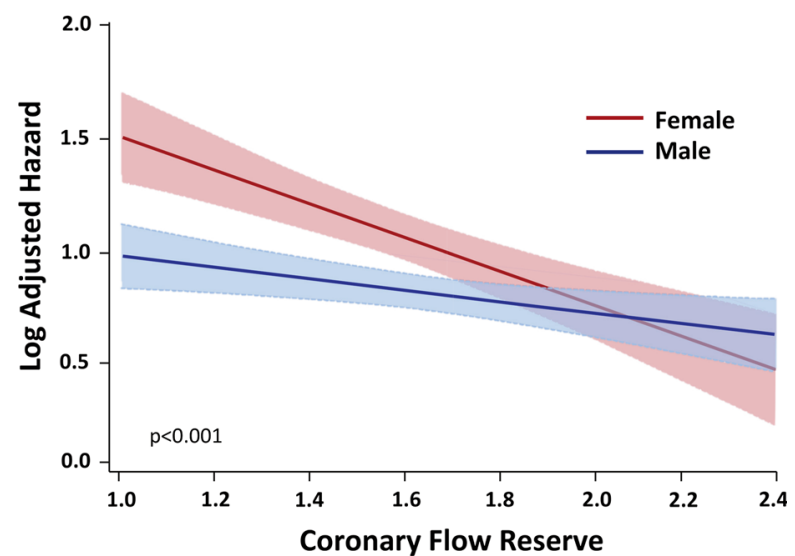

Figure 7. Log adjusted hazard for major adverse cardiovascular events in female versus male patients varies as a function of PET MPI coronary flow reserve. The effect of sex on cardiovascular events was modified by CFR such that differences in outcomes between women and men were amplified for patients with very low CFR, $<1.6(P$ for interaction $=0.04)$. $C F R$, coronary flow reserve; $H R$, hazard ratio estimated from the linear interaction of CFR and sex. Reproduced with permission. $^{35}$

Multicenter Imaging Study for Evaluation of Chest Pain (PROMISE) trial evaluated 10,003 patients $(52.7 \%$ women) randomized to stress testing $(67.3 \%$ with stress SPECT MPI) or CCTA with the results reporting similar rates of adverse events (death, acute coronary syndromes, or procedural complications) by randomized test strategy $(P=0.75) .{ }^{126}$ In this trial, the cumulative 3 -year costs were similar for patients randomized to stress testing versus CCTA. ${ }^{127}$ Although the estimated cost of index testing with CCTA was lower than that with an initial functional strategy (including ETT alone, stress MPI, or stress echocardiography), CCTA use was associated with more downstream catheterizations and revascularizations, leading to similar costs averaged over follow-up time. These results have implications for the largely community-based enrollment of the PROMISE trial, where 3-year costs were similar across diagnostic test modalities and support similar evaluation and care costs for a functional versus anatomical testing strategy in a heterogeneous population of patients with suspected CAD. However, given the high prevalence of nonobstructive CAD in symptomatic women, ${ }^{128}$ and the higher rate of invasive coronary angiography for CCTA in the PROMISE trial, more research is warranted to determine the added contribution of detecting flowlimiting atherosclerotic plaques or small-vessel ischemia. This underscores the critical need for randomized and comparative trial data in female patients.

\section{Radiation Dose Reduction with MPI in Women}

Awareness of a large rise in population exposure to ionizing radiation from medical diagnostic procedures over the last three decades ${ }^{129}$ has led to concerns about downstream cancer risk, particularly among younger patients and women (Figure 8). ${ }^{130,131}$ This has resulted in renewed focus on efforts to decrease patient radiation doses to levels that are as low as reasonably achievable (ALARA). The exposure of women and men to ionizing radiation has been the focus of several documents from ASNC on patient-centered imaging (see summary of effective doses in Table 2). ${ }^{132-135}$ For the clinician, concern exists as to whether women have an increased projected cancer risk associated with radiation exposure when compared to men. However, recent estimates do not demonstrate a differential risk from MPI in women as compared to men, ${ }^{136}$ particularly when AUC are followed. ${ }^{137}$ A number of consensus statements are available on this subject, ${ }^{130,138}$ including those from ASNC. ${ }^{132,133,139}$

Methods to reduce radiation exposure: Patient testing. The exposure to radiation of patients undergoing a medical diagnostic evaluation is justified only in the setting of appropriate procedural use and optimized dose-reduction strategies. With regard to the former, issues regarding radiation exposure are dependent on the clinical benefit of testing and the evidentiary standards supporting the clinical indication for testing. To reduce unnecessary testing and radiation exposure, the ACC's AUC or the American College of Radiology's Appropriateness Criteria, as detailed above, provide primary means for justification of procedural use. ${ }^{9,16}$ Data suggest that performing testing in patients outside these accepted criteria (rarely appropriate) results in a very low diagnostic yield, as the vast percentage of studies is normal. ${ }^{140,141}$ Thus, the principal means of reducing radiation exposure among women is to restrict utilization of MPI to those meeting appropriate indications for testing.

With regard to the latter, minimizing radiation exposure for patients is of considerable importance for optimal patient safety, regardless of sex. All clinicians involved in the patient's care must be involved in this process, from the healthcare provider ordering the test to the nuclear cardiologist performing and interpreting the test, to whom responsibility ultimately falls for selecting testing protocols, equipment, and tracers. ASNC has advocated that the median patient dose per study should be $<9$ millisieverts $(\mathrm{mSv}){ }^{132}$ The next section will highlight specific methods to reduce radiation dose, such as the use of stress-only imaging or the expanded 


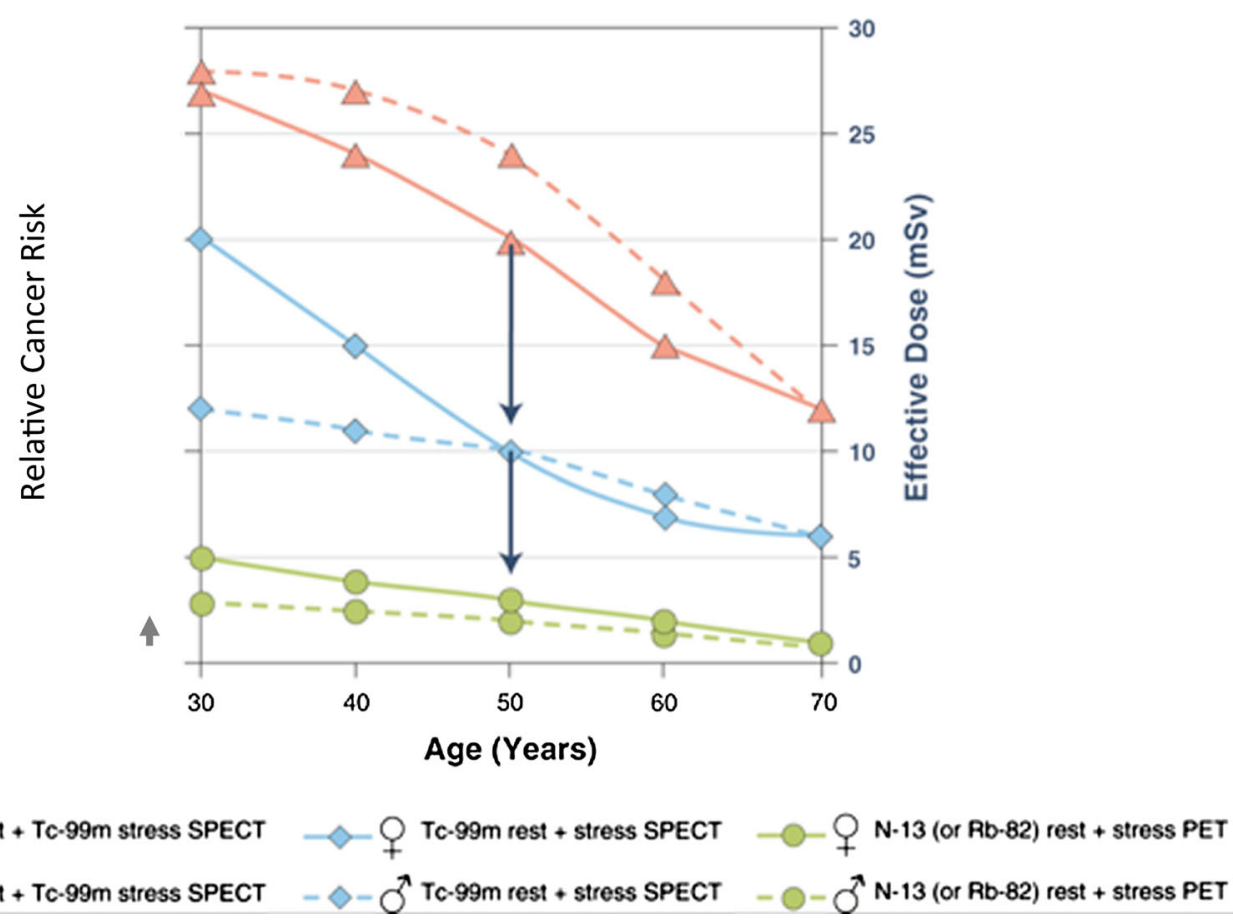

Figure 8. Relative lifetime cancer risk in men $(\widehat{\delta})$ and women $(+9)$ as a function of age for different myocardial perfusion imaging tracers and protocols. Using Tc-99m instead of ${ }^{201}$ TI SPECT decreases the radiation effective dose (arrows) and cancer risk by a factor of 2 . Further reduction by a factor of 2 to 3 is achieved by using current PET tracers. Adapted with permission. ${ }^{131}$

Table 2. Typical radiation exposure, as measured by effective dose, from rest-stress MPI, CCTA, and angiography in women. Adapted with permission ${ }^{5}$

\section{Typical radiation exposure (by Effective Dose) from cardiac imaging in women}

\section{Effective dose, $\mathrm{mSv}$}

Annual background exposure

Invasive coronary angiography

Rest-stress MPI SPECT

Dual-isotope MPI SPECT-should be avoided

Technetium Tc 99m (NaI camera)

Technetium Tc 99m (CZT camera)

Stress-only MPI SPECT

Rest-stress MPI PET

Rubidium Rb82

Nitrogen N13

CCTA

Overall

With dose-reduction techniques

Coronary artery calcium scoring

$$
\begin{aligned}
& \approx 3 \\
& \approx 7 \\
& \approx 22 \\
& \approx 11 \\
& \approx 6 \\
& \approx 1-3 \\
& \approx 3 \\
& \approx 2 \\
& \approx 10 \\
& <2-5 \\
& \approx 1-2
\end{aligned}
$$

CCTA, coronary computed tomographic angiography; $M P I$, myocardial perfusion imaging; Nal, sodium iodine; $C Z T$, cadmium zinc telluride; PET, positron emission tomography; SPECT, single-photon emission computed tomography 
application of cardiac PET MPI, to aid any laboratory in achieving ASNC goals. Recent worldwide surveys from the International Atomic Energy Agency-sponsored (IAEA) Nuclear Cardiology Protocols Cross-Sectional Study (INCAPS) registry suggest that there is considerable room for improvement in radiation dosereduction practices for both women and men. ${ }^{142}$ From the INCAPS registry, including 7,911 patients from 65 countries, mean effective dose was slightly lower for women $(9.6 \mathrm{mSv})$ as compared to men $(10.3 \mathrm{mSv}$; $P<0.001)$. While stress-only MPI was performed more often in women than in men $(12.5 \%$ versus $8.4 \%$; $P<0.001$ ), camera-based dose-reduction strategies were used less frequently in women than in men $(59 \%$ versus 66\%; $P<0.0001)$. These data support that additional improvements in radiation dose reduction are possible for both women and men.

Methods to reduce radiation exposure: Imaging protocols. The most widely utilized tracers are ${ }^{99 \mathrm{~m}} \mathrm{Tc}$ based, with a typical rest/stress protocol resulting in an effective dose ranging from 8 to $16 \mathrm{mSv}$. By comparison, MPI protocols involving ${ }^{201} \mathrm{Tl}$ are in the 11 to $23 \mathrm{mSv}$ range. ${ }^{143}$ Because of this increased exposure to ionizing radiation without added benefit in diagnostic or prognostic accuracy, the use of ${ }^{201} \mathrm{Tl}$ or dual-isotope (rest: ${ }^{201} \mathrm{Tl} / \mathrm{stress}:{ }^{99 \mathrm{~m}} \mathrm{Tc}$ ) protocols is discouraged for most patients by ASNC consensus statements. ${ }^{139,143}$ Nonetheless, surveys indicate that ${ }^{201} \mathrm{Tl}$ remains an isotope commonly utilized in the United States. ${ }^{144-148}$ An immediate method to reduce radiation exposure, therefore, is to eliminate ${ }^{201} \mathrm{Tl}$ use as a primary imaging tracer in all laboratories, as recommended by ASNC. ${ }^{139}$

Stress-only or stress-first imaging. In most laboratories, a patient undergoes the rest study first, followed by stress, despite data that only $9 \%$ to $34 \%$ of studies performed are positive for ischemia or infarction. ${ }^{149,150}$ Thus, performing the stress as the initial imaging study (particularly with attenuation correction techniques), and the rest only when needed may be a reasonable means of increasing laboratory efficiency and reducing patient radiation exposure in the appropriately selected patient. Regardless of whether the initial stress dose is high ( 24 to 30 millicuries, $\mathrm{mCi}$ ) or low (8 to $12 \mathrm{mCi}$ ), substantial radiation reduction is achieved by avoidance of the rest study. ${ }^{62,151-157}$ Despite the overwhelming data supporting stress before rest, currently only a small proportion of laboratories are using this protocol. ${ }^{14,142,144}$

Image processing and software for existing systems. New advances have demonstrated that using software to enhance image quality for existing cameras can also reduce radiation exposure by decreasing isotope dosage by approximately $25 \%$ $75 \% .^{80,158,159}$ Replacement of filtered back projection with iterative reconstruction (ordered subset expectation minimization, OSEM) potentially requires $25 \%$ to $75 \%$ less counts to produce similar images. ${ }^{160}$ Wide-beam reconstruction and similar software solutions compensate for the complicated beam angles and spread of counts when reconstructing the image, and can achieve high-image quality with reduced radiation. ${ }^{161}$ Algorithms that combine multiple levels of processing by utilizing OSEM, noise reduction algorithms, collimator design, scatter modeling, and attenuation correction can produce high-quality images during half-time acquisition. Data from a variety of studies have demonstrated that these applications result in excellent image quality with per-patient radiation exposure in the range of 4 to 8 mSv. 80,158

New camera systems. Consideration for potential radiation reduction should be a factor when purchasing new equipment. In contrast to standard Anger sodium iodine (NaI) cameras, new solid-state detectors have been developed which utilize CZT arrays. Data suggest that higher count sensitivity of CZT cameras can produce images of comparable diagnostic quality with $15 \%$ to $30 \%$ of standard radiation doses. ${ }^{162-164}$ Ultra-low-dose protocols involving the use of stress-first imaging in appropriately selected patients with CZT cameras have led to substantial reductions in effective radiation exposure, to as low as $1 \mathrm{mSv}$ per study. ${ }^{165,166}$

PET MPI to reduce radiation exposure. A major strength of PET imaging, especially for the evaluation of the female patient, is that enhanced image quality and diagnostic capability are feasible while limiting patient exposure to ionizing radiation. Rest/ stress perfusion imaging using the PET radiopharmaceuticals ${ }^{82} \mathrm{Rb}$ or nitrogen-13 $\left({ }^{13} \mathrm{~N}\right)$ ammonia, with halflives of 1.2 and 9.8 minutes, respectively, results in an effective dose of radiation at or below annual background exposure levels $(\leq 3 \mathrm{mSv})$ (Table 2). ${ }^{5}$ This is significantly lower than that associated with a rest/stress conventional SPECT study using ${ }^{99 \mathrm{~m}} \mathrm{Tc}(\approx 11 \mathrm{mSv})$ or with diagnostic invasive coronary angiography $(\approx 7 \mathrm{mSv})$, and commensurate with ALARA principles as recommended by the Joint Commission on Diagnostic Imaging for cardiac imaging procedures. ${ }^{129,167}$

Summary recommendations for reducing radiation exposure in women undergoing MPI are detailed in Table 3. 
Table 3. Strategies for reducing radiation exposure in women undergoing radionuclide myocardial perfusion imaging

1. Use AUC to guide patient selection for nuclear cardiology procedures.

2. Use technetium-based tracers for SPECT MPI studies. Avoid use of thallium-based and dual-isotope SPECT protocols.

3. Consider stress-first MPI (especially with attenuation correction techniques) for select patients without evidence of prior MI or cardiomyopathy.

4. Implement iterative reconstruction algorithms for use with existing SPECT technology.

5. Use high-sensitivity solid-state CZT SPECT cameras and/or PET MPI where available.

6. Continually review nuclear laboratory practices to implement dose-reduction strategies to decrease patient radiation doses to levels that are as low as reasonably achievable (ALARA) and approaching levels of natural background radiation ( $3 \mathrm{mSV} /$ year) whenever possible.

AUC, appropriate use criteria; SPECT, single-photon emission computed tomography; MPI, myocardial perfusion imaging; $M I$, myocardial infarction; $C Z T$, cadmium zinc telluride; $P E T$, positron emission tomography; $A L A R A$, as low as reasonably achievable

\section{COMPARATIVE TRIAL EVIDENCE OF MPI VERSUS OTHER APPROACHES IN SIHD}

There have been numerous randomized trials of imaging in the evaluation of suspected SIHD published in the last several years, many of which included the use of stress MPI imaging. ${ }^{15,168-170}$ As already briefly described, the WOMEN trial randomized 824 symptomatic women to a strategy of index exercise ECG versus exercise SPECT MPI. ${ }^{15}$ At 2 years of follow-up, there were no differences in the rate of CAD death, MI, or hospitalization for acute coronary syndromes or heart failure $(1.7 \%$ in the exercise ECG arm versus $2.3 \%$ in the exercise SPECT MPI arm, $P=0.59$ ). Nearly 1 in 5 women randomized to the exercise ECG arm had a follow-up SPECT MPI scan, largely, for those with indeterminate or positive test results. Findings from this trial revealed that a first strategy of exercise ECG followed by selective SPECT MPI can effectively manage low-risk women. Sizeable cost savings were achieved using this approach of the exercise ECG first compared to index SPECT MPI testing, with a cost savings for the diagnostic evaluation of approximately $\$ 300(P<0.0001)$.

In a secondary analysis from the single-center Clinical Evaluation of MAgnetic Resonance imaging in Coronary heart disease (CE-MARC) trial, 235 women underwent adenosine SPECT MPI, a multiparametric cardiovascular magnetic resonance imaging (CMR) examination (including balanced steady-state free precession cine imaging, rest/stress perfusion, 3D CMR angiography, and late gadolinium enhancement), and invasive coronary angiography. ${ }^{168,171}$ The results indicated a sensitivity and specificity for SPECT MPI of $59 \%$ and $84 \%$ versus $89 \%$ and $84 \%$ for the multiparametric CMR $(P<0.0001$ and $P=0.77$, respectively. This higher accuracy of CMR is likely attributable to single-site expertise, but requires further validation with a comprehensive nuclear examination, which is considered the standard of care in diagnostic testing. In a related example from the PROMISE trial, communitybased interpretation of stress test findings (67\% stress MPI) resulted in a 2.1-year rate of death, MI, or hospitalization for unstable angina of $5.1 \%$ and $1.9 \%$ for women with positive and negative stress-test findings $(P<0.0001) .{ }^{169,170}$ These data support that a multicenter, community-based interpretation can effectively stratify risk in women, a strong statement for the accuracy of MPI testing across the United States.

Several recent randomized trials have compared stress testing approaches to CCTA strategies of care, revealing no statistically significant difference in outcome over the nearly 2 years of follow-up for both the Scottish COmputed Tomography of the HEART (SCOTHEART) and PROMISE trials. ${ }^{126,172}$ This supports that contemporary diagnostic testing practices including MPI are effective for evaluating patients with SIHD. Findings from these two trials revealed a lower rate of follow-up invasive angiography in those undergoing stress testing; which was performed prior to randomization in $85 \%$ of patients in the SCOT-HEART trial. For example, in the PROMISE trial, the rate of invasive coronary angiography was $12.2 \%$ in the CCTA arm and $8.1 \%$ in the stress testing arm $(P=0.022)$. Moreover, the rate of coronary revascularization was nearly twofold higher in the CCTA arm as compared to the stress testing arm within the PROMISE trial (6.2\% versus $3.2 \%)$. Although stress testing included evaluations with and without imaging, these data support the use of functional testing approaches as gatekeepers to invasive angiography and selective revascularization, and are consistent with ischemia-guided management. In a secondary analysis from the PROMISE trial, no difference in the 
primary outcome was observed by randomization for women $(P=0.75)$ or men $(P=0.76) .{ }^{169,173}$

Recently, the CE-MARC 2 trial provided further evidence for the comparative effectiveness of CMR versus SPECT MPI. ${ }^{174}$ In 1,202 symptomatic patients (46.9\% women) with a mean pretest likelihood of $49.5 \%$, reduction in unnecessary angiography when compared to the National Institute of Health and Care Excellence (NICE) guidelines was similarly low with SPECT $(16.2 \%$ [95\% CI, $13.0 \%$ to $19.8 \%$ ] as well as CMR (17.7\% [95\% CI, $14.4 \%$ to $21.4 \%]) .{ }^{175}$

It is important to note that enrollment of women in clinical trials and in clinical research in general is often lower than optimal. The recent studies highlighted above serve to remind the scientific community of the importance of active recruitment of women into clinical trials. Doing so may allow sex-specific data to become available and to facilitate identification of potentially unique differences among women and men, depending on the specifics of trial or registry design. Women-only trials in SIHD should also be encouraged, especially for those phenotypes that appear to be particularly prevalent in women, including symptomatic nonobstructive CAD and HFpEF.

\section{FUTURE DIRECTIONS: SIHD WITHOUT OBSTRUCTIVE CAD}

The future of MPI for women with suspected or known SIHD must include an increased emphasis on strategies to ensure low-radiation exposure, a high degree of accuracy, and defining strategies of care for women with and without obstructive CAD. Technical improvements in image quality for women, including for obese patients, are critical for accurate diagnostic and prognostic evaluation of this large sector of the U.S. population. Focused research must reveal the degree to which PET (or possibly SPECT) MPI with CFR may identify women with angiographically normal coronary arteries with definable CMD, which may occur either in the presence or absence of obstructive CAD or myocardial diseases. ${ }^{176}$ More so for women than men, there is a large pool of patients with nonobstructive and obstructive CAD who report a heavy burden of symptoms; ${ }^{128,177}$ women not only have a nearly $20 \%$ higher prevalence of angina, but have a rate of persistent or worsening symptoms that are nearly double that of men. ${ }^{15,177-180}$ Moreover, the extent to which women with mild epicardial CAD-including high-risk

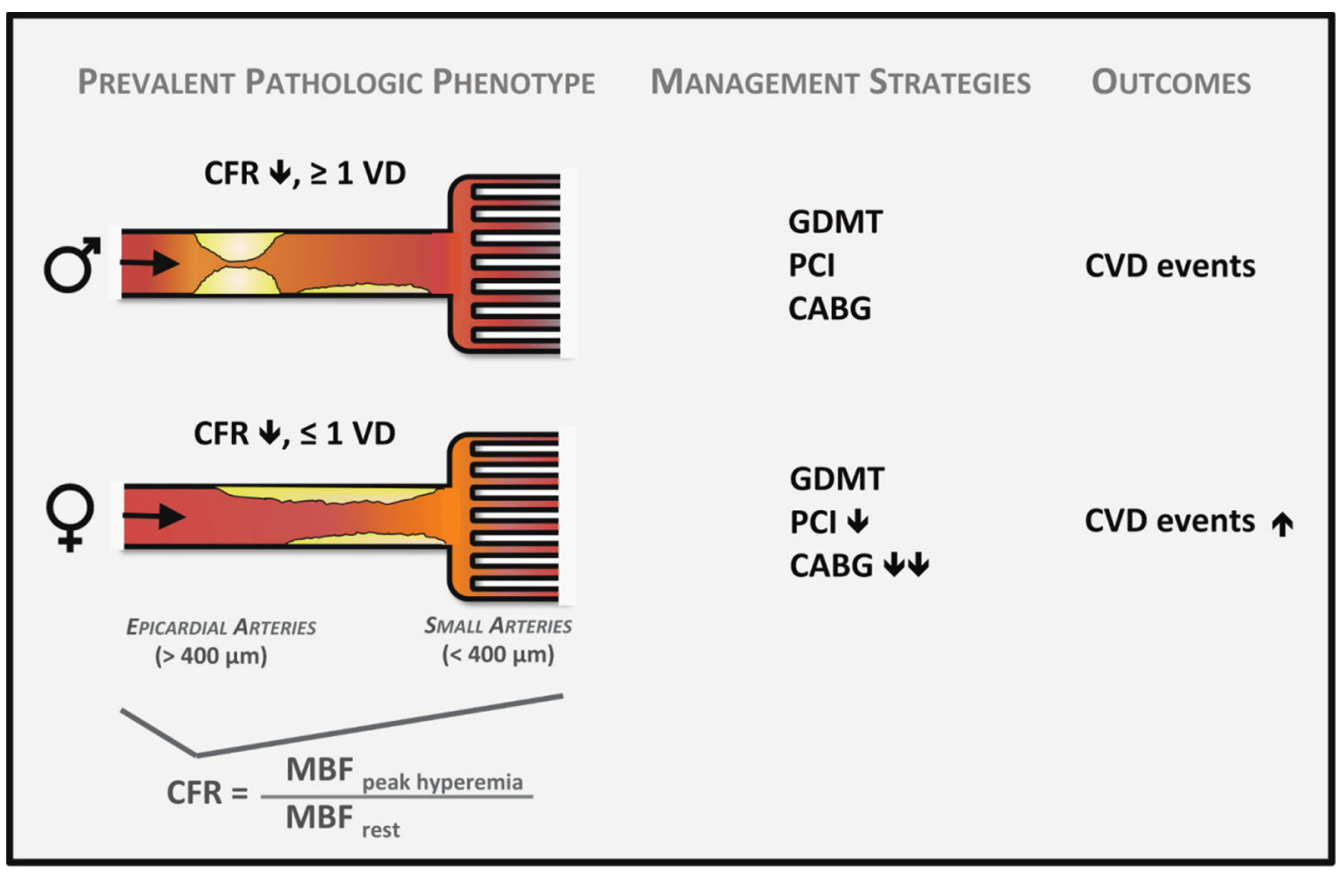

Figure 9. Conceptual model of prevalent pathologic phenotypes in women and men with ischemic heart disease and potential impact on cardiovascular management strategies and outcomes. $C A B G$, coronary artery bypass surgery; $C F R$, coronary flow reserve; $C V D$, cardiovascular disease; $G D M T$, guideline-directed medical therapy; $M B F$, myocardial blood flow; $P C I$, percutaneous coronary intervention; $V D$, vessel disease. Reproduced with permission. ${ }^{35}$ 


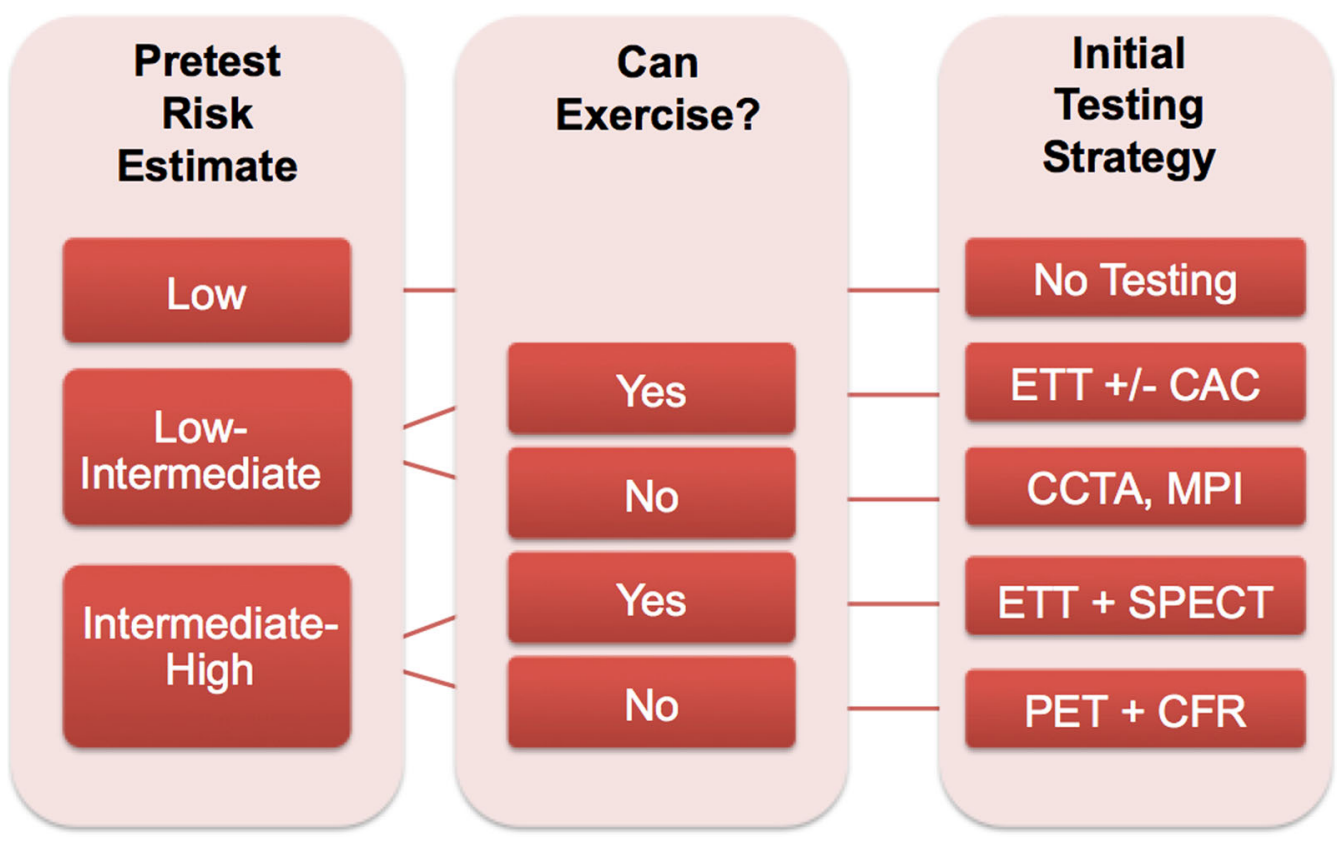

Figure 10. Proposed clinical algorithm for the preferred initial diagnostic evaluation of symptomatic women with suspected stable ischemic heart disease with or without obstructive CAD. *Assumes test is locally available and ALARA principles for radiation dose reduction strategies (i.e., prospective ECG-gated CT, avoidance of dual-isotope and ${ }^{201}$ TI SPECT protocols, and preference for CZT and stress-only SPECT, or PET) are utilized whenever possible. **In cases where an anatomical strategy (i.e., CCTA or invasive coronary angiography) demonstrates absence of obstructive CAD, consider PET-CFR evaluation for coronary microvascular dysfunction. ***If nonobstructive $\mathrm{CAD}$ and/or coronary microvascular dysfunction is present, refer for guidelinedirected therapies (where paucity of data and guidelines suggests more research is needed to define optimal therapies).

atherosclerosis plaque features-may benefit from the addition of CFR to correlate with their symptom burden and future IHD risk is unknown, but constitutes a worthwhile research goal. Understanding the contribution of functional and anatomical parameters associated with CAD is likely to represent the key to devising optimal evaluation algorithms for women with SIHD. As such, strategies are needed not only to detect atherosclerosis and its functional significance in women, but also to guide treatment of women with functionally and prognostically significant nonobstructive or less severely obstructive CAD (Figure 9). Recent treatment trials of women with suspected CMD have largely been negative. ${ }^{181}$ Ongoing efforts are focused on defining the distinct clinical syndrome of angina or ischemia with no obstructive CAD (INOCA), ${ }^{182}$ as well as identifying current knowledge gaps and next steps for developing evidence-based therapies. With the advent of PET/CT (as hybrid or serial imaging), multiparametric imaging approaches may be possible to integrate MPI and CFR with anatomical atherosclerotic plaque to uniquely identify at-risk women.

\section{CONCLUSIONS}

IHD poses a major threat to women across their lifespans, and we are only beginning to recognize the importance of expanding conventional tools developed more than a half-century ago for the diagnosis and management of (primarily obstructive) CAD, to IHD in women. Women with ongoing chest pain due to either obstructive or nonobstructive coronary disease have increased mortality compared to asymptomatic patients with disease. This updated consensus statement provides a state-of-the-art review on the available evidence of the role of MPI for the evaluation of stable IHD in symptomatic women.

The ACC's multimodality AUC document outlines imaging methods for the detection and risk assessment of SIHD in men and women and indications for invasive coronary angiography. ${ }^{9}$ For women, the evidence base for SPECT and PET MPI is robust and supports accurate detection of obstructive CAD, effective risk stratification, and hopefully more appropriate utilization of invasive procedures. Integration of multiple parameters, particularly the addition of CFR and CT, into an MPI 


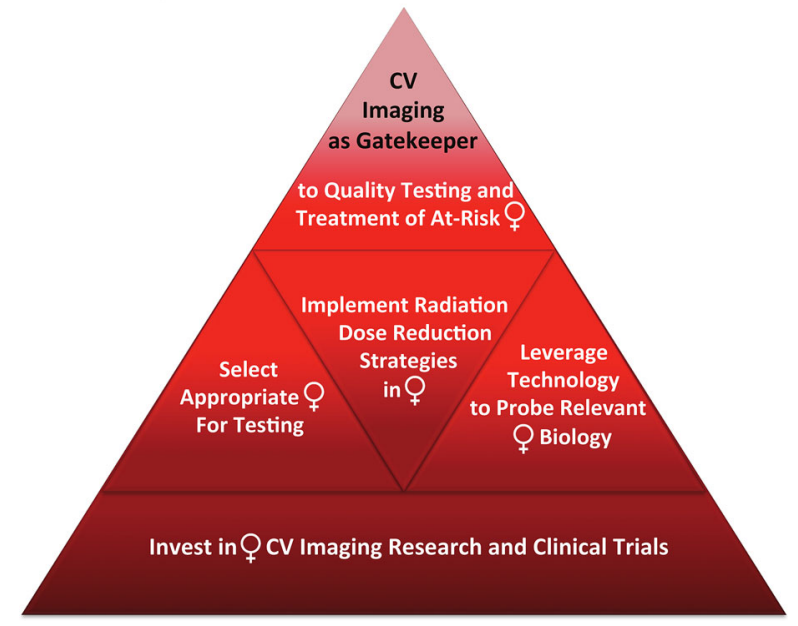

Figure 11. Top Priorities for Cardiovascular Imaging in Women.

examination (e.g., using PET/CT, or serial examinations interrogating aspects of both function and anatomy) may improve detection of SIHD in women and provide management guidance for patients with nonobstructive epicardial CAD and CMD. An updated clinical algorithm for the initial diagnostic evaluation of symptomatic women with SIHD with or without obstructive CAD is proposed in Figure 10. Top priorities for cardiovascular imaging in women are summarized in Figure 11. Future evidence on MPI-guided strategies of care tailored to symptomatic women may prove useful not only in the evaluation, but also in the optimal management of SIHD in this large and growing sector of the population.

\section{Acknowledgements}

This work was supported in part by K12 HD051959 Building Interdisciplinary Research Careers in Women's Health and a Harvard Medical School Diversity Partnership Faculty Fellowship to Dr Taqueti.

\section{Disclosures}

Dr. Sharmila Dorbala receives grant support from Astellas Pharma and has investment in General Electric stocks. Dr. David Wolinsky receives grant support from Astellas Pharma, serves on the speakers' bureau of Astellas Pharma and the steering committee for Adenosine Therapeutics. Dr. Gary V. Heller receives royalties from McGraw Hill and is a consultant to Morristown Medical Center. Dr. Heller is a medical advisor to Molecular Imaging Services and a research officer for the nonprofit group, Intersocietal Accreditation Commission. Dr. Timothy Bateman receives royalties from ExSPECT II attenuation correction, ImagenPro/MD/Q/ 3D, and support from Astellas Pharma and GE Healthcare. Dr. Bateman is on the advisory board for Lantheus Medical
Imaging and is the medical director of Cardiovascular Imaging Technologies, LLC. Dr. Lawrence Phillips receives consulting fees from Merck, Inc. All other contributors have nothing relevant to disclose.

\section{References}

1. Baldassarre LA, Raman SV, Min JK, Mieres JH, Gulati M, Wenger NK, et al. Noninvasive imaging to evaluate women with stable ischemic heart disease. JACC Cardiovasc Imaging 2016;9:421-35.

2. Bairey Merz CN, Regitz-Zagrosek V. The case for sex- and gender-specific Med. JAMA Intern Med 2014;174:1348-9.

3. Taqueti VR, Di Carli MF. Radionuclide myocardial perfusion imaging for the evaluation of patients with known or suspected coronary artery disease in the era of multimodality cardiovascular imaging. Prog Cardiovasc Dis 2015;57:644-53.

4. Shaw LJ, Tandon S, Rosen S, Mieres JH. Evaluation of suspected ischemic heart disease in symptomatic women. Can J Cardiol 2014;30:729-37.

5. Mieres JH, Gulati M, Bairey Merz N, Berman DS, Gerber TC, Hayes SN, et al. Role of noninvasive testing in the clinical evaluation of women with suspected ischemic heart disease: A consensus statement from the American Heart Association. Circulation 2014;130:350-79.

6. Taqueti VR, Dorbala S. The role of positron emission tomography in the evaluation of myocardial ischemia in women. J Nucl Cardiol 2016;23:1008-15.

7. Fihn SD, Gardin JM, Abrams J, Berra K, Blankenship JC, Dallas AP, et al. 2012 ACCF/AHA/ACP/AATS/PCNA/SCAI/STS guideline for the diagnosis and management of patients with stable ischemic heart disease: A report of the American College of Cardiology Foundation/American Heart Association Task Force on Practice Guidelines, and the American College of Physicians, American Association for Thoracic Surgery, Preventive Cardiovascular Nurses Association, Society for Cardiovascular Angiography and Interventions, and Society of Thoracic Surgeons. J Am Coll Cardiol 2012;60:e44-164.

8. Mieres JH, Shaw LJ, Hendel RC, Miller DD, Bonow RO, Berman DS, et al. American Society of Nuclear Cardiology consensus statement: Task force on women and coronary artery disease-the role of myocardial perfusion imaging in the clinical evaluation of coronary artery disease in women [correction]. J Nucl Cardiol 2003;10:95-101.

9. Wolk MJ, Bailey SR, Doherty JU, Douglas PS, Hendel RC, Kramer CM, et al. ACCF/AHA/ASE/ASNC/HFSA/HRS/SCAI/ SCCT/SCMR/STS 2013 multimodality appropriate use criteria for the detection and risk assessment of stable ischemic heart disease: a report of the American College of Cardiology Foundation Appropriate Use Criteria Task Force, American Heart Association, American Society of Echocardiography, American Society of Nuclear Cardiology, Heart Failure Society of America, Heart Rhythm Society, Society for Cardiovascular Angiography and Interventions, Society of Cardiovascular Computed Tomography, Society for Cardiovascular Magnetic Resonance, and Society of Thoracic Surgeons. J Am Coll Cardiol 2014;63:380-406.

10. Ouyang P, Wenger NK, Taylor D, Rich-Edwards JW, Steiner M, Shaw LJ, et al. Strategies and methods to study female-specific cardiovascular health and disease: A guide for clinical scientists. Biol Sex Differ 2016;7:19. 
11. Mosca L, Banka CL, Benjamin EJ, Berra K, Bushnell C, Dolor $\mathrm{RJ}$, et al. Evidence-based guidelines for cardiovascular disease prevention in women: 2007 update. Circulation 2007;115:12.

12. Mosca L, Benjamin EJ, Berra K, Bezanson JL, Dolor RJ, LloydJones DM, et al. Effectiveness-based guidelines for the prevention of cardiovascular disease in women-2011 update: A guideline from the American Heart Association. J Am Coll Cardiol 2011;57:1404-23.

13. Wilmot KA, O'Flaherty M, Capewell S, Ford ES, Vaccarino V. Coronary heart disease mortality declines in the United States From 1979 through 2011: Evidence for stagnation in young adults, especially women. Circulation 2015;132:997-1002.

14. Hendel RC, Berman DS, Di Carli MF, Heidenreich PA, Henkin RE, Pellikka PA, et al. ACCF/ASNC/ACR/AHA/ASE/SCCT/ SCMR/SNM 2009 appropriate use criteria for cardiac radionuclide imaging: A report of the American College of Cardiology Foundation Appropriate Use Criteria Task Force, the American Society of Nuclear Cardiology, the American College of Radiology, the American Heart Association, the American Society of Echocardiography, the Society of Cardiovascular Computed Tomography, the Society for Cardiovascular Magnetic Resonance, and the Society of Nuclear Medicine. Circulation 2009;119:e561-87.

15. Shaw LJ, Mieres JH, Hendel RH, Boden WE, Gulati M, Veledar E, et al. Comparative effectiveness of exercise electrocardiography with or without myocardial perfusion single photon emission computed tomography in women with suspected coronary artery disease: Results from the What Is the Optimal Method for Ischemia Evaluation in Women (WOMEN) trial. Circulation 2011;124:1239-49.

16. Woodard PK, White RD, Abbara S, Araoz PA, Cury RC, Dorbala $\mathrm{S}$, et al. ACR appropriateness criteria chronic chest pain-low to intermediate probability of coronary artery disease. J Am Coll Radiol 2013;10:329-34.

17. Berwick DM, Nolan TW, Whittington J. The triple aim: Care, health, and cost. Health Aff 2008;27:759-69.

18. Garcia EV. Are SPECT measurements of myocardial blood flow and flow reserve ready for clinical use? Eur J Nucl Med Mol Imaging 2014;41:2291-3.

19. Dolor RJ, Patel MR, Melloni C, Chatterjee R, McBroom AJ, Musty MD, et al. Noninvasive technologies for the diagnosis of coronary artery disease in women Rockville (MD): AHRQ Comparative Effectiveness Reviews 2012; Report No.: 12EHC034-EF.

20. Sanders GD, Patel MR, Chatterjee R, Ross AK, Bastian LA, Coeytaux RR, et al. Noninvasive technologies for the diagnosis of coronary artery disease in women: Identification of future research needs from comparative effectiveness review No 58 . Rockville (MD): AHRQ comparative effectiveness reviews 2013; Report No.: 13-EHC072-EF.

21. Sharir T, Kang X, Germano G, Bax JJ, Shaw LJ, Gransar H, et al. Prognostic value of poststress left ventricular volume and ejection fraction by gated myocardial perfusion SPECT in women and men: Gender-related differences in normal limits and outcomes. J Nucl Cardiol 2006;13:495-506.

22. Rivero A, Santana C, Folks RD, Esteves F, Verdes L, Esiashvili $\mathrm{S}$, et al. Attenuation correction reveals gender-related differences in the normal values of transient ischemic dilation index in restexercise stress sestamibi myocardial perfusion imaging. J Nucl Cardiol 2006;13:338-44

23. Van Train KF, Maddahi J, Berman DS, Kiat H, Areeda J, Prigent F, et al. Quantitative analysis of tomographic stress thallium-201 myocardial scintigrams: A multicenter trial. J Nucl Med 1990;31:1168-79.
24. Sharma P, Patel CD, Karunanithi S, Maharjan S, Malhotra A. Comparative accuracy of $\mathrm{CT}$ attenuation-corrected and non-attenuation-corrected SPECT myocardial perfusion imaging. Clin Nucl Med 2012;37:332-8.

25. Ficaro EP, Fessler JA, Shreve PD, Kritzman JN, Rose PA, Corbett JR. Simultaneous transmission/emission myocardial perfusion tomography. Diagnostic accuracy of attenuation-corrected $99 \mathrm{mTc}$-sestamibi single-photon emission computed tomography. Circulation 1996;93:463-73.

26. Masood Y, Liu YH, Depuey G, Taillefer R, Araujo LI, Allen S, et al. Clinical validation of SPECT attenuation correction using $\mathrm{x}$-ray computed tomography-derived attenuation maps: multicenter clinical trial with angiographic correlation. J Nucl Cardiol 2005; 12:676-86.

27. Links JM, DePuey EG, Taillefer R, Becker LC. Attenuation correction and gating synergistically improve the diagnostic accuracy of myocardial perfusion SPECT. J Nucl Cardiol 2002;9:183-7.

28. Hendel RC, Berman DS, Cullom SJ, Follansbee W, Heller GV, Kiat H, et al. Multicenter clinical trial to evaluate the efficacy of correction for photon attenuation and scatter in SPECT myocardial perfusion imaging. Circulation 1999;99:2742-9.

29. Berman DS, Kang X, Nishina H, Slomka PJ, Shaw LJ, Hayes SW, et al. Diagnostic accuracy of gated Tc-99m sestamibi stress myocardial perfusion SPECT with combined supine and prone acquisitions to detect coronary artery disease in obese and nonobese patients. J Nucl Cardiol 2006;13:191-201.

30. Slomka PJ, Nishina H, Abidov A, Hayes SW, Friedman JD, Berman DS, et al. Combined quantitative supine-prone myocardial perfusion SPECT improves detection of coronary artery disease and normalcy rates in women. $\mathrm{J}$ Nucl Cardiol 2007;14:44-52.

31. Ben-Haim S, Almukhailed O, Neill J, Slomka P, Allie R, Shiti D, et al. Clinical value of supine and upright myocardial perfusion imaging in obese patients using the D-SPECT camera. J Nucl Cardiol 2014;21:478-85.

32. Grossman GB, Garcia EV, Bateman TM, Heller GV, Johnson LL, Folks RD, et al. Quantitative Tc-99m sestamibi attenuationcorrected SPECT: Development and multicenter trial validation of myocardial perfusion stress gender-independent normal database in an obese population. J Nucl Cardiol 2004;11:263-72.

33. Heller GV, Bateman TM, Johnson LL, Cullom SJ, Case JA, Galt $\mathrm{JR}$, et al. Clinical value of attenuation correction in stress-only Tc99m sestamibi SPECT imaging. J Nucl Cardiol 2004;11:273-81.

34. Pepine CJ, Anderson RD, Sharaf BL, Reis SE, Smith KM, Handberg EM, et al. Coronary microvascular reactivity to adenosine predicts adverse outcome in women evaluated for suspected ischemia results from the National Heart, Lung and Blood Institute WISE (Women's Ischemia Syndrome Evaluation) study. J Am Coll Cardiol 2010;55:2825-32.

35. Taqueti V, Shaw LJ, Murthy VL, Shah NR, Foster CR, Hainer J, et al. Excess cardiovascular risk in women relative to men referred for coronary angiography is associated with impaired coronary flow reserve from diffuse versus obstructive coronary artery disease. Circulation 2017;135:566-77.

36. Kohli P, Gulati M. Exercise stress testing in women: Going back to the basics. Circulation 2010;122:2570-80.

37. Grzybowski A, Puchalski W, Zieba B, Gruchala M, Fijalkowski $\mathrm{M}$, Storoniak K, et al. How to improve noninvasive coronary artery disease diagnostics in premenopausal women? The influence of menstrual cycle on ST depression, left ventricle contractility, and chest pain observed during exercise echocardiography in women with angina and normal coronary angiogram. Am Heart J 2008;156:964 e1-5. 
38. Morise AP, Beto R. The specificity of exercise electrocardiography in women grouped by estrogen status. Int $\mathbf{J}$ Cardiol 1997;60:55-65.

39. Barolsky SM, Gilbert CA, Faruqui A, Nutter DO, Schlant RC. Differences in electrocardiographic response to exercise of women and men: A non-Bayesian factor. Circulation 1979;60:1021-7.

40. Mora S, Redberg RF, Cui Y, Whiteman MK, Flaws JA, Sharrett $\mathrm{AR}$, et al. Ability of exercise testing to predict cardiovascular and all-cause death in asymptomatic women: A 20-year follow-up of the lipid research clinics prevalence study. JAMA 2003;290:1600-7.

41. Kwok Y, Kim C, Grady D, Segal M, Redberg R. Meta-analysis of exercise testing to detect coronary artery disease in women. Am J Cardiol 1999;83:660-6.

42. Abbott BG, Afshar M, Berger AK, Wackers FJ. Prognostic significance of ischemic electrocardiographic changes during adenosine infusion in patients with normal myocardial perfusion imaging. J Nucl Cardiol 2003;10:9-16.

43. Klodas E, Miller TD, Christian TF, Hodge DO, Gibbons RJ. Prognostic significance of ischemic electrocardiographic changes during vasodilator stress testing in patients with normal SPECT images. J Nucl Cardiol 2003;10:4-8.

44. Amanullah AM, Kiat H, Friedman JD, Berman DS. Adenosine technetium-99m sestamibi myocardial perfusion SPECT in women: Diagnostic efficacy in detection of coronary artery disease. J Am Coll Cardiol 1996;27:803-9.

45. Travin MI, Katz MS, Moulton AW, Miele NJ, Sharaf BL, Johnson LL. Accuracy of dipyridamole SPECT imaging in identifying individual coronary stenoses and multivessel disease in women versus men. J Nucl Cardiol 2000;7:213-20.

46. Cerqueira MD, Nguyen P, Staehr P, Underwood SR, Iskandrian AE. Investigators A-MT. Effects of age, gender, obesity, and diabetes on the efficacy and safety of the selective A2A agonist regadenoson versus adenosine in myocardial perfusion imaging integrated ADVANCE-MPI trial results. JACC Cardiovasc Imaging 2008;1:307-16.

47. Santana-Boado C, Candell-Riera J, Castell-Conesa J, AguadeBruix S, Garcia-Burillo A, Canela T, et al. Diagnostic accuracy of technetium-99m-MIBI myocardial SPECT in women and men. J Nucl Med 1998;39:751-5.

48. Taillefer R, DePuey EG, Udelson JE, Beller GA, Latour Y, Reeves F. Comparative diagnostic accuracy of Tl-201 and Tc99m sestamibi SPECT imaging (perfusion and ECG-gated SPECT) in detecting coronary artery disease in women. J Am Coll Cardiol 1997;29:69-77.

49. Chae SC, Heo J, Iskandrian AS, Wasserleben V, Cave V. Identification of extensive coronary artery disease in women by exercise single-photon emission computed tomographic (SPECT) thallium imaging. J Am Coll Cardiol 1993;21:1305-11.

50. Iskandrian AE, Heo J, Nallamothu N. Detection of coronary artery disease in women with use of stress single-photon emission computed tomography myocardial perfusion imaging. J Nucl Cardiol 1997;4:329-35.

51. Mullani NA, Caras D, Ahn C, Lundberg G, Page D, Kleinman D, et al. Fewer women than men have positive SPECT and PET cardiac findings among patients with no history of heart disease. J Nucl Med 2000;41:263-8.

52. Hansen CL, Crabbe D, Rubin S. Lower diagnostic accuracy of thallium-201 SPECT myocardial perfusion imaging in women: An effect of smaller chamber size. J Am Coll Cardiol 1996;28:1214-9.

53. Hachamovitch R, Berman DS, Kiat H, Bairey CN, Cohen I, Cabico A, et al. Effective risk stratification using exercise myocardial perfusion SPECT in women: Gender-related differences in prognostic nuclear testing. $\mathrm{J}$ Am Coll Cardiol 1996;28:34-44.

54. Santos MT, Parker MW, Heller GV. Evaluating gender differences in prognosis following SPECT myocardial perfusion imaging among patients with diabetes and known or suspected coronary disease in the modern era. $\mathrm{J}$ Nucl Cardiol 2013;20:1021-9.

55. Pancholy SB, Fattah AA, Kamal AM, Ghods M, Heo J, Iskandrian AS. Independent and incremental prognostic value of exercise thallium single-photon emission computed tomographic imaging in women. J Nucl Cardiol 1995;2:110-6.

56. Marwick TH, Shaw LJ, Lauer MS, Kesler K, Hachamovitch R, Heller GV, et al. The noninvasive prediction of cardiac mortality in men and women with known or suspected coronary artery disease. Economics of noninvasive diagnosis (END) study group. Am J Med 1999;106:172-8.

57. Metz LD, Beattie M, Hom R, Redberg RF, Grady D, Fleischmann KE. The prognostic value of normal exercise myocardial perfusion imaging and exercise echocardiography: A metaanalysis. J Am Coll Cardiol 2007;49:227-37.

58. Shaw LJ, Hage FG, Berman DS, Hachamovitch R, Iskandrian A. Prognosis in the era of comparative effectiveness research: Where is nuclear cardiology now and where should it be? J Nucl Cardiol 2012;19:1026-43.

59. Sharir T, Germano G, Kavanagh PB, Lai S, Cohen I, Lewin HC, et al. Incremental prognostic value of post-stress left ventricular ejection fraction and volume by gated myocardial perfusion single photon emission computed tomography. Circulation 1999;100:1035-42.

60. Valeti US, Miller TD, Hodge DO, Gibbons RJ. Exercise singlephoton emission computed tomography provides effective risk stratification of elderly men and elderly women. Circulation 2005;111:1771-6.

61. Cerci MS, Cerci JJ, Cerci RJ, Pereira Neto CC, Trindade E, Delbeke D, et al. Myocardial perfusion imaging is a strong predictor of death in women. JACC Cardiovasc Imaging. 2011;4:880-8

62. Chang SM, Nabi F, Xu J, Raza U, Mahmarian JJ. Normal stressonly versus standard stress/rest myocardial perfusion imaging: Similar patient mortality with reduced radiation exposure. J Am Coll Cardiol 2010;55:221-30.

63. Duvall WL, Wijetunga MN, Klein TM, Razzouk L, Godbold J, Croft LB, et al. The prognosis of a normal stress-only Tc-99m myocardial perfusion imaging study. J Nucl Cardiol 2010;17:370-7.

64. Chang SM, Nabi F, Xu J, Peterson LE, Achari A, Pratt CM, et al. The coronary artery calcium score and stress myocardial perfusion imaging provide independent and complementary prediction of cardiac risk. J Am Coll Cardiol 2009;54:1872-82.

65. He ZX, Hedrick TD, Pratt CM, Verani MS, Aquino V, Roberts R, et al. Severity of coronary artery calcification by electron beam computed tomography predicts silent myocardial ischemia. Circulation 2000;101:244-51.

66. Ghadri JR, Fiechter M, Veraguth K, Gebhard C, Pazhenkottil AP, Fuchs TA, et al. Coronary calcium score as an adjunct to nuclear myocardial perfusion imaging for risk stratification before noncardiac surgery. J Nucl Med 2012;53:1081-6.

67. Anand DV, Lim E, Hopkins D, Corder R, Shaw LJ, Sharp P, et al. Risk stratification in uncomplicated type 2 diabetes: Prospective evaluation of the combined use of coronary artery calcium imaging and selective myocardial perfusion scintigraphy. Eur Heart J 2006;27:713-21.

68. Berman DS, Wong ND, Gransar H, Miranda-Peats R, Dahlbeck $\mathrm{J}$, Hayes SW, et al. Relationship between stress-induced 
myocardial ischemia and atherosclerosis measured by coronary calcium tomography. J Am Coll Cardiol 2004;44:923-30.

69. Rozanski A, Gransar H, Wong ND, Shaw LJ, Miranda-Peats R, Polk D, et al. Clinical outcomes after both coronary calcium scanning and exercise myocardial perfusion scintigraphy. J Am Coll Cardiol 2007;49:1352-61.

70. Ramakrishna G, Miller TD, Breen JF, Araoz PA, Hodge DO, Gibbons RJ. Relationship and prognostic value of coronary artery calcification by electron beam computed tomography to stressinduced ischemia by single photon emission computed tomography. Am Heart J 2007;153:807-14.

71. Einstein AJ, Johnson LL, Bokhari S, Son J, Thompson RC, Bateman TM, et al. Agreement of visual estimation of coronary artery calcium from low-dose CT attenuation correction scans in hybrid PET/CT and SPECT/CT with standard Agatston score. J Am Coll Cardiol 2010;56:1914-21.

72. Lubbers M, Dedic A, Coenen A, Galema T, Akkerhuis J, Bruning $\mathrm{T}$, et al. Calcium imaging and selective computed tomography angiography in comparison to functional testing for suspected coronary artery disease: The multicentre, randomized CRESCENT trial. Eur Heart J 2016;37:1232-43.

73. Greenland P, Bonow RO. How low-risk is a coronary calcium score of zero? Circulation 2008;117:1627-9.

74. Kelkar AA, Schultz WM, Khosa F, Schulman-Marcus J, O'Hartaigh BW, Gransar H, et al. Long-term prognosis after coronary artery calcium scoring among low-intermediate risk women and men. Circ Cardiovasc Imaging 2016;9:e003742.

75. Gaemperli O, Husmann L, Schepis T, Koepfli P, Valenta I, Jenni $\mathrm{W}$, et al. Coronary CT angiography and myocardial perfusion imaging to detect flow-limiting stenoses: A potential gatekeeper for coronary revascularization? Eur Heart J 2009;30:2921-9.

76. Schuijf JD, Wijns W, Jukema JW, Atsma DE, de Roos A, Lamb $\mathrm{HJ}$, et al. Relationship between noninvasive coronary angiography with multi-slice computed tomography and myocardial perfusion imaging. J Am Coll Cardiol 2006;48:2508-14.

77. Gaemperli O, Schepis T, Valenta I, Koepfli P, Husmann L, Scheffel $\mathrm{H}$, et al. Functionally relevant coronary artery disease: Comparison of 64-section CT angiography with myocardial perfusion SPECT. Radiology 2008;248:414-23.

78. Husmann L, Herzog BA, Gaemperli O, Tatsugami F, Burkhard $\mathrm{N}$, Valenta I, et al. Diagnostic accuracy of computed tomography coronary angiography and evaluation of stress-only single-photon emission computed tomography/computed tomography hybrid imaging: Comparison of prospective electrocardiogramtriggering vs. retrospective gating. Eur Heart J 2009;30:600-7.

79. Pazhenkottil AP, Nkoulou RN, Ghadri JR, Herzog BA, Buechel RR, Kuest SM, et al. Prognostic value of cardiac hybrid imaging integrating single-photon emission computed tomography with coronary computed tomography angiography. Eur Heart J 2011;32:1465-71.

80. Dorbala S, Blankstein R, Skali H, Park MA, Fantony J, Mauceri $\mathrm{C}$, et al. Approaches to reducing radiation dose from radionuclide myocardial perfusion imaging. J Nucl Med 2015;56:592-9.

81. Ben-Haim S, Murthy VL, Breault C, Allie R, Sitek A, Roth N, et al. Quantification of myocardial perfusion reserve using dynamic SPECT imaging in humans: A feasibility study. J Nucl Med 2013;54:873-9.

82. Duvall WL, Slomka PJ, Gerlach JR, Sweeny JM, Baber U, Croft LB, et al. High-efficiency SPECT MPI: Comparison of automated quantification, visual interpretation, and coronary angiography. J Nucl Cardiol 2013;20:763-73.

83. Chowdhury FU, Vaidyanathan S, Bould M, Marsh J, Trickett C, Dodds K, et al. Rapid-acquisition myocardial perfusion scintigraphy (MPS) on a novel gamma camera using multipinhole collimation and miniaturized cadmium-zinc-telluride (CZT) detectors: Prognostic value and diagnostic accuracy in a 'realworld' nuclear cardiology service. Eur Heart J Cardiovasc Imaging 2014;15:275-83

84. Gimelli A, Bottai M, Quaranta A, Giorgetti A, Genovesi D, Marzullo P. Gender differences in the evaluation of coronary artery disease with a cadmium-zinc telluride camera. Eur J Nucl Med Mol Imaging 2013;40:1542-8.

85. Dorbala S, Di Carli MF. Cardiac PET perfusion: Prognosis, risk stratification, and clinical management. Semin Nucl Med 2014;44:344-57.

86. Di Carli MF, Dorbala S, Meserve J, El Fakhri G, Sitek A, Moore SC. Clinical myocardial perfusion PET/CT. J Nucl Med 2007;48:783-93.

87. Parker MW, Iskandar A, Limone B, Perugini A, Kim H, Jones C, et al. Diagnostic accuracy of cardiac positron emission tomography versus single photon emission computed tomography for coronary artery disease: A bivariate meta-analysis. Circ Cardiovasc Imaging 2012;5:700-7.

88. Mc Ardle BA, Dowsley TF, deKemp RA, Wells GA, Beanlands RS. Does rubidium-82 PET have superior accuracy to SPECT perfusion imaging for the diagnosis of obstructive coronary disease?: A systematic review and meta-analysis. J Am Coll Cardiol 2012;60:1828-37

89. Bairey Merz CN, Shaw LJ, Reis SE, Bittner V, Kelsey SF, Olson M, et al. Insights from the NHLBI-sponsored women's ischemia syndrome evaluation (WISE) study: Part II: Gender differences in presentation, diagnosis, and outcome with regard to gender-based pathophysiology of atherosclerosis and macrovascular and microvascular coronary disease. J Am Coll Cardiol 2006;47:S21-9.

90. Shaw LJ, Bairey Merz CN, Pepine CJ, Reis SE, Bittner V, Kelsey $\mathrm{SF}$, et al. Insights from the NHLBI-sponsored women's ischemia syndrome evaluation (WISE) study: Part I: GENDER differences in traditional and novel risk factors, symptom evaluation, and gender-optimized diagnostic strategies. J Am Coll Cardiol 2006; 47:S4-20

91. Dorbala S, Di Carli MF, Beanlands RS, Merhige ME, Williams BA, Veledar E, et al. Prognostic value of stress myocardial perfusion positron emission tomography: Results from a multicenter observational registry. J Am Coll Cardiol 2013;61:176-84.

92. Dorbala S, Hachamovitch R, Curillova Z, Thomas D, Vangala D, Kwong RY, et al. Incremental prognostic value of gated $\mathrm{Rb}-82$ positron emission tomography myocardial perfusion imaging over clinical variables and rest LVEF. JACC Cardiovasc Imaging 2009;2:846-54.

93. Lertsburapa K, Ahlberg AW, Bateman TM, Katten D, Volker L, Cullom SJ, et al. Independent and incremental prognostic value of left ventricular ejection fraction determined by stress gated rubidium 82 PET imaging in patients with known or suspected coronary artery disease. J Nucl Cardiol 2008;15:745-53.

94. Marwick TH, Shan K, Patel S, Go RT, Lauer MS. Incremental value of rubidium- 82 positron emission tomography for prognostic assessment of known or suspected coronary artery disease. Am J Cardiol 1997;80:865-70.

95. Yoshinaga K, Chow BJ, Williams K, Chen L, deKemp RA, Garrard L, et al. What is the prognostic value of myocardial perfusion imaging using rubidium- 82 positron emission tomography? J Am Coll Cardiol 2006;48:1029-39.

96. Van Tosh A, Supino PG, Nichols KJ, Garza D, Horowitz SF, Reichek N. Prognosis of a normal positron emission tomography $82 \mathrm{Rb}$ myocardial perfusion imaging study in women with no history of coronary disease. Cardiology 2010;117:301-6.

97. Kay J, Dorbala S, Goyal A, Fazel R, Di Carli MF, Einstein AJ, et al. Influence of sex on risk stratification with stress myocardial 
perfusion Rb-82 positron emission tomography: Results from the PET (Positron Emission Tomography) Prognosis Multicenter Registry. J Am Coll Cardiol 2013;62:1866-76.

98. Dorbala S, Vangala D, Sampson U, Limaye A, Kwong R, Di Carli MF. Value of vasodilator left ventricular ejection fraction reserve in evaluating the magnitude of myocardium at risk and the extent of angiographic coronary artery disease: A 82Rb PET/ CT study. J Nucl Med 2007;48:349-58.

99. Bairey Merz CN. Sex, death, and the diagnosis gap. Circulation 2014;130:740-2.

100. Gulati M, Cooper-DeHoff RM, McClure C, Johnson BD, Shaw LJ, Handberg EM, et al. Adverse cardiovascular outcomes in women with nonobstructive coronary artery disease: A report from the Women's Ischemia Syndrome Evaluation Study and the St James Women Take Heart Project. Arch Intern Med 2009;169:843-50.

101. Pepine CJ, Ferdinand KC, Shaw LJ, Light-McGroary KA, Shah RU, Gulati M, et al. Emergence of nonobstructive coronary artery disease: A woman's problem and need for change in definition on angiography. J Am Coll Cardiol 2015;66:1918-33.

102. von Mering GO, Arant CB, Wessel TR, McGorray SP, Bairey Merz CN, Sharaf BL, et al. Abnormal coronary vasomotion as a prognostic indicator of cardiovascular events in women: Results from the national heart, lung, and blood institute-sponsored women's ischemia syndrome evaluation (WISE). Circulation 2004;109:722-5

103. Gould KL. Does coronary flow trump coronary anatomy? JACC Cardiovasc Imaging 2009;2:1009-23.

104. Murthy VL, Naya M, Foster CR, Hainer J, Gaber M, Di Carli G, et al. Improved cardiac risk assessment with noninvasive measures of coronary flow reserve. Circulation 2011;124:2215-24.

105. Ziadi MC, Dekemp RA, Williams KA, Guo A, Chow BJ, Renaud $\mathrm{JM}$, et al. Impaired myocardial flow reserve on rubidium-82 positron emission tomography imaging predicts adverse outcomes in patients assessed for myocardial ischemia. J Am Coll Cardiol 2011;58:740-8.

106. Fukushima K, Javadi MS, Higuchi T, Lautamaki R, Merrill J, Nekolla SG, et al. Prediction of short-term cardiovascular events using quantification of global myocardial flow reserve in patients referred for clinical 82Rb PET perfusion imaging. J Nucl Med 2011;52:726-32.

107. Herzog BA, Husmann L, Valenta I, Gaemperli O, Siegrist PT, Tay FM, et al. Long-term prognostic value of $13 \mathrm{~N}$-ammonia myocardial perfusion positron emission tomography added value of coronary flow reserve. J Am Coll Cardiol 2009;54:150-6.

108. Naya M, Murthy VL, Taqueti VR, Foster CR, Klein J, Garber M, et al. Preserved coronary flow reserve effectively excludes highrisk coronary artery disease on angiography. J Nucl Med 2014;55:248-55.

109. Taqueti VR, Di Carli MF. Clinical significance of noninvasive coronary flow reserve assessment in patients with ischemic heart disease. Curr Opin Cardiol 2016;31:662-9.

110. Murthy VL, Lee BC, Sitek A, Naya M, Moody J, Polavarapu V, et al. Comparison and prognostic validation of multiple methods of quantification of myocardial blood flow with $82 \mathrm{Rb}$ PET. J Nucl Med 2014;55:1952-8.

111. Taqueti VR, Hachamovitch R, Murthy VL, Naya M, Foster CR, Hainer J, et al. Global coronary flow reserve is associated with adverse cardiovascular events independently of luminal angiographic severity and modifies the effect of early revascularization. Circulation 2015;131:19-27.

112. Li S, Fonarow GC, Mukamal KJ, Liang L, Schulte PJ, Smith EE, et al. Sex and race/ethnicity-related disparities in care and outcomes after hospitalization for coronary artery disease among older adults. Circ Cardiovasc Qual Outcomes 2016;9:S36-44.

113. Smilowitz NR, Sampson BA, Abrecht CR, Siegfried JS, Hochman JS, Reynolds HR. Women have less severe and extensive coronary atherosclerosis in fatal cases of ischemic heart disease: An autopsy study. Am Heart J 2011;161:681-8.

114. Murthy VL, Naya M, Taqueti VR, Foster CR, Gaber M, Hainer J, et al. Effects of sex on coronary microvascular dysfunction and cardiac outcomes. Circulation 2014;129:2518-27.

115. Naya M, Murthy VL, Foster CR, Gaber M, Klein J, Hainer J, et al. Prognostic interplay of coronary artery calcification and underlying vascular dysfunction in patients with suspected coronary artery disease. J Am Coll Cardiol 2013;61:2098-106.

116. Taqueti VR, Everett BM, Murthy VL, Gaber M, Foster CR, Hainer J, et al. Interaction of impaired coronary flow reserve and cardiomyocyte injury on adverse cardiovascular outcomes in patients without overt coronary artery disease. Circulation 2015; 131:528-35.

117. Taqueti VR, Groarke J, Osborne M, Shah A, Murthy V, Hainer J, et al. Impaired coronary flow reserve is associated with diastolic dysfunction and HFpEF outcomes in patients without overt CAD. JACC 2017;S69:2562 (abstr).

118. Sheikine Y, Di Carli MF. Integrated PET/CT in the assessment of etiology and viability in ischemic heart failure. Curr Heart Fail Rep 2008;5:136-42.

119. Hulten E, Aslam S, Osborne M, Abbasi S, Bittencourt MS, Blankstein R. Cardiac sarcoidosis-state of the art review. Cardiovasc Diagn Ther 2016;6:50-63.

120. Xie JX, Shaw LJ. Measuring diagnostic health care costs in stable coronary artery disease: Should we follow the money? Ann Intern Med 2016;165:147-8.

121. Lee AJ, Michail M, Quaderi SA, Richardson JA, Aggarwal SK, Speechly-Dick ME. Implementation of NICE clinical guideline 95 for assessment of stable chest pain in a rapid access chest pain clinic reduces the mean number of investigations and cost per patient. Open Heart 2015;2:e000151.

122. Shaw LJ, Hachamovitch R, Berman DS, Marwick TH, Lauer MS, Heller GV, et al. The economic consequences of available diagnostic and prognostic strategies for the evaluation of stable angina patients: An observational assessment of the value of precatheterization ischemia. Economics of noninvasive diagnosis (END) multicenter study group. J Am Coll Cardiol 1999;33:661-9.

123. Shaw LJ, Heller GV, Travin MI, Lauer M, Marwick T, Hachamovitch R, et al. Cost analysis of diagnostic testing for coronary artery disease in women with stable chest pain. Economics of noninvasive diagnosis (END) study group. J Nucl Cardiol 1999;6:559-69.

124. Merhige ME, Breen WJ, Shelton V, Houston T, D'Arcy BJ, Perna AF. Impact of myocardial perfusion imaging with PET and (82) $\mathrm{Rb}$ on downstream invasive procedure utilization, costs, and outcomes in coronary disease management. J Nucl Med 2007;48:1069-76.

125. Shaw LJ, Marwick TH, Berman DS, Sawada S, Heller GV, Vasey $C$, et al. Incremental cost-effectiveness of exercise echocardiography vs SPECT imaging for the evaluation of stable chest pain. Eur Heart J 2006;27:2448-58.

126. Douglas PS, Hoffmann U. Anatomical versus functional testing for coronary artery disease. N Engl J Med 2015;373:91.

127. Mark DB, Federspiel JJ, Cowper PA, Anstrom KJ, Hoffmann U, Patel MR, et al. Economic outcomes with anatomical versus functional diagnostic testing for coronary artery disease. Ann Intern Med 2016;165:94-102. 
128. Jespersen L, Hvelplund A, Abildstrom SZ, Pedersen F, Galatius S, Madsen JK, et al. Stable angina pectoris with no obstructive coronary artery disease is associated with increased risks of major adverse cardiovascular events. Eur Heart J 2012;33:73444.

129. Schauer DA, Linton OW. NCRP, Report No. 160, ionizing radiation exposure of the Population of the United States, medical exposure - are we doing less with more, and is there a role for health physicists? Health Phys 2009;97:1-5.

130. Fazel R, Gerber TC, Balter S, Brenner DJ, Carr JJ, Cerqueira $\mathrm{MD}$, et al. Approaches to enhancing radiation safety in cardiovascular imaging: A scientific statement from the American Heart Association. Circulation 2014;130:1730-48.

131. deKemp RA, Wells RG, Beanlands RS. Women image wisely: The $3 \mathrm{mSv}$ challenge for nuclear cardiology. JACC Cardiovasc Imaging 2016;9:385-7.

132. Cerqueira MD, Allman KC, Ficaro EP, Hansen CL, Nichols KJ, Thompson $\mathrm{RC}$, et al. Recommendations for reducing radiation exposure in myocardial perfusion imaging. $\mathrm{J}$ Nucl Cardiol 2010;17:709-18.

133. DePuey EG. Patient-centered imaging: More relevant (and perhaps more elusive) than ever. J Nucl Cardiol 2014;21:661-5.

134. Fazel R, Shaw LJ. Radiation exposure from radionuclide myocardial perfusion imaging: Concerns and solutions. J Nucl Cardiol 2011;18:562-5.

135. Fazel R, Dilsizian V, Einstein AJ, Ficaro EP, Henzlova M, Shaw LJ. Strategies for defining an optimal risk-benefit ratio for stress myocardial perfusion SPECT. J Nucl Cardiol 2011;18:385-92.

136. Berrington de Gonzalez A, Kim KP, Smith-Bindman R, McAreavey D. Myocardial perfusion scans: Projected population cancer risks from current levels of use in the United States. Circulation 2010;122:2403-10.

137. Doukky R, Frogge N, Appis A, et al. Impact of appropriate use on the estimated radiation risk to men and women undergoing radionuclide myocardial perfusion imaging. J Nucl Med 2016;57:1251-7.

138. Gerber TC, Carr JJ, Arai AE, Dixon RL, Ferrari VA, Gomes AS et al. Ionizing radiation in cardiac imaging: a science advisory from the American Heart Association Committee on Cardiac Imaging of the Council on Clinical Cardiology and Committee on Cardiovascular Imaging and Intervention of the Council on Cardiovascular Radiology and Intervention. Circulation 2009; 119:1056-65.

139. Depuey EG, Mahmarian JJ, Miller TD, Einstein AJ, Hansen CL, Holly TA, et al. Patient-centered imaging. J Nucl Cardiol 2012;19:185-215.

140. Doukky R, Hayes K, Frogge N, Balakrishnan G, Dontaraju VS, Rangel MO, et al. Impact of appropriate use on the prognostic value of single-photon emission computed tomography myocardial perfusion imaging. Circulation 2013;128:1634-43.

141. Doukky R, Hayes K, Frogge N. Appropriate use criteria for SPECT myocardial perfusion imaging: Are they appropriate for women? J Nucl Cardiol 2015.

142. Shi L, Dorbala S, Paez D, Shaw LJ, Zukotynski KA, Pascual TN, et al. Gender differences in radiation dose from nuclear cardiology studies across the world: Findings from the INCAPS Registry. JACC Cardiovasc Imaging 2016;9:376-84.

143. Henzlova MJ, Duvall WL, Einstein AJ, Travin MI, Verberne HJ. ASNC imaging guidelines for SPECT nuclear cardiology procedures: Stress, protocols, and tracers. J Nucl Cardiol 2016;23:606-39.

144. Jerome SD, Tilkemeier PL, Farrell MB, Shaw LJ. Nationwide laboratory adherence to myocardial perfusion imaging radiation dose reduction practices: A report from the Intersocietal
Accreditation Commission Data Repository. JACC Cardiovasc Imaging 2015;8:1170-6.

145. Mercuri M, Pascual TN, Mahmarian JJ, Shaw LJ, Dondi M, Paez $\mathrm{D}$, et al. Estimating the reduction in the radiation burden from nuclear cardiology through use of stress-only imaging in the United States and worldwide. JAMA Intern Med 2016;176:26973.

146. Mercuri M, Pascual TN, Mahmarian JJ, Shaw LJ, Rehani MM, Paez D, et al. Comparison of radiation doses and best-practice use for myocardial perfusion imaging in US and non-US Laboratories: Findings from the IAEA (International Atomic Energy Agency) nuclear cardiology protocols study. JAMA Intern Med 2016;176:266-9.

147. Einstein AJ, Tilkemeier P, Fazel R, Rakotoarivelo H, Shaw LJ, American Society of Nuclear C. Radiation safety in nuclear cardiology-current knowledge and practice: Results from the 2011 American Society of Nuclear Cardiology member survey. JAMA Intern Med 2013;173:1021-3.

148. Tilkemeier P, Green J, Einstein AJ, Fazel R, Reames P, Shaw LJ. The evolving practice of nuclear cardiology: Results from the 2011 ASNC member survey. J Nucl Cardiol 2012;19:1170-5.

149. Rozanski A, Gransar H, Hayes SW, Min J, Friedman JD, Thomson LE, et al. Temporal trends in the frequency of inducible myocardial ischemia during cardiac stress testing: 1991 to 2009 . J Am Coll Cardiol 2013;61:1054-65.

150. Duvall WL, Rai M, Ahlberg AW, O’Sullivan DM, Henzlova MJ. A multi-center assessment of the temporal trends in myocardial perfusion imaging. J Nucl Cardiol 2015;22:539-51.

151. Mahmarian JJ. Implementation of stress-only imaging: What will it take? J Nucl Cardiol 2015.

152. Mathur S, Heller GV, Bateman TM, Ruffin R, Yekta A, Katten $\mathrm{D}$, et al. Clinical value of stress-only Tc-99m SPECT imaging: importance of attenuation correction. J Nucl Cardiol 2013;20:2737.

153. McMahon SR, Kikut J, Pinckney RG, Keating FK. Feasibility of stress only rubidium-82 PET myocardial perfusion imaging. J Nucl Cardiol 2013;20:1069-75.

154. Pazhenkottil AP, Kaufmann PA, Gaemperli O. Attenuation correction in stress-only myocardial perfusion imaging. J Nucl Cardiol 2016.

155. Henzlova MJ, Croft LB, Duvall WL. Stress-only imaging: Faster, cheaper, less radiation. So what's the hold up? J Nucl Cardiol 2013;20:17-9.

156. Duvall WL, Hiensch RJ, Levine EJ, Croft LB, Henzlova MJ. The prognosis of a normal Tl-201 stress-only SPECT MPI study. J Nucl Cardiol 2012;19:914-21.

157. Henzlova MJ, Duvall WL, Einstein AJ, Travin MI, Verberne HJ. ASNC imaging guidelines for SPECT nuclear cardiology procedures: Stress, protocols, and tracers. J Nucl Cardiol 2016;23:606-39.

158. Slomka PJ, Dey D, Duvall WL, Henzlova MJ, Berman DS, Germano G. Advances in nuclear cardiac instrumentation with a view towards reduced radiation exposure. Curr Cardiol Rep 2012;14:208-16

159. Slomka PJ, Patton JA, Berman DS, Germano G. Advances in technical aspects of myocardial perfusion SPECT imaging. J Nucl Cardiol 2009;16:255-76.

160. DePuey EG, Gadiraju R, Clark J, Thompson L, Anstett F, Shwartz SC. Ordered subset expectation maximization and wide beam reconstruction "half-time", gated myocardial perfusion SPECT functional imaging: A comparison to "full-time", filtered backprojection. J Nucl Cardiol 2008;15:547-63.

161. Venero CV, Heller GV, Bateman TM, McGhie AI, Ahlberg AW, Katten D, et al. A multicenter evaluation of a new post- 
processing method with depth-dependent collimator resolution applied to full-time and half-time acquisitions without and with simultaneously acquired attenuation correction. J Nucl Cardiol 2009; 16:714-25.

162. Einstein AJ, Blankstein R, Andrews H, et al. Comparison of image quality, myocardial perfusion, and left ventricular function between standard imaging and single-injection ultra-low-dose imaging using a high-efficiency SPECT camera: The MILLISIEVERT study. J Nucl Med 2014;55:1430-7.

163. Duvall WL, Croft LB, Ginsberg ES, Einstein AJ, Guma KA, George $\mathrm{T}$, et al. Reduced isotope dose and imaging time with a high-efficiency CZT SPECT camera. J Nucl Cardiol 2011;18: 847-57.

164. Duvall WL, Sweeny JM, Croft LB, Ginsberg E, Guma KA, Henzlova MJ. Reduced stress dose with rapid acquisition CZT SPECT MPI in a non-obese clinical population: Comparison to coronary angiography. J Nucl Cardiol 2012;19:19-27.

165. Einstein AJ, Blankstein R, Andrews H, et al. Comparison of image quality, myocardial perfusion, and left ventricular function between standard imaging and single-injection ultra-low-dose imaging using a high-efficiency SPECT camera: The MILLISIEVERT study. J Nucl Med 2014;55:1430-7.

166. Thompson RC, O'Keefe JH, McGhie AI, Bybee KA, Thompson EC, Bateman TM. Reduction of SPECT MPI radiation dose using contemporary protocols and technology. JACC Cardiovasc Imaging 2017; 2259.

167. The Joint Commission. Diagnostic imaging standards. Published August 10, 2015. https://www.jointcommission.org/assets/1/18/ AHC_DiagImagingRpt_MK_20150806.pdf. Accessed March 6, 2017.

168. Greenwood JP, Motwani M, Maredia N, Brown JM, Everett CC, Nixon J, et al. Comparison of cardiovascular magnetic resonance and single-photon emission computed tomography in women with suspected coronary artery disease from the clinical evaluation of magnetic resonance imaging in coronary heart disease (CE-MARC) Trial. Circulation 2014;129:1129-38.

169. Pagidipati NJ, Hemal K, Coles A, Mark DB, Dolor RJ, Pellikka $\mathrm{PA}$, et al. Sex differences in functional and CT angiography testing in patients with suspected coronary artery disease. J Am Coll Cardiol 2016;67:2607-16.

170. Hemal K, Pagidipati NJ, Coles A, Dolor RJ, Mark DB, Pellikka $\mathrm{PA}$, et al. Sex differences in demographics, risk factors, presentation, and noninvasive testing in stable outpatients with suspected coronary artery disease: Insights from the PROMISE trial. JACC Cardiovasc Imaging 2016;9:337-46.

171. Greenwood JP, Maredia N, Younger JF, Brown JM, Nixon J, Everett CC, et al. Cardiovascular magnetic resonance and singlephoton emission computed tomography for diagnosis of coronary heart disease (CE-MARC): A prospective trial. Lancet 2012;379:453-60.
172. SCOT Heart investigators. CT coronary angiography in patients with suspected angina due to coronary heart disease (SCOTHEART): An open-label, parallel-group, multicentre trial. Lancet 2015;385:2383-91.

173. Hemal K, Pagidipati NJ, Coles A, Dolor RJ, Mark DB, Pellikka PA, et al. Sex differences in demographics, risk factors, presentation, and noninvasive testing in stable outpatients with suspected coronary artery disease: Insights from the PROMISE trial. JACC Cardiovasc Imaging 2016;9:337-46.

174. Ripley DP, Brown JM, Everett CC, Bijsterveld P, Walker S, Sculpher M, et al. Rationale and design of the clinical evaluation of magnetic resonance imaging in coronary heart disease 2 trial (CE-MARC 2): A prospective, multicenter, randomized trial of diagnostic strategies in suspected coronary heart disease. Am Heart J 2015;169:17-24 e1.

175. Greenwood JP, Ripley DP, Berry C, McCann GP, Plein S, Bucciarelli-Ducci C, et al. Effect of care guided by cardiovascular magnetic resonance, myocardial perfusion scintigraphy, or NICE guidelines on subsequent unnecessary angiography rates: The CE-MARC 2 randomized clinical trial. JAMA 2016;316: 1051-60.

176. Camici PG, Crea F. Coronary microvascular dysfunction. N Engl J Med 2007;356:830-40.

177. Hemingway H, Langenberg C, Damant J, Frost C, Pyorala K, Barrett-Connor E. Prevalence of angina in women versus men: A systematic review and meta-analysis of international variations across 31 countries. Circulation 2008;117:1526-36.

178. Johnson BD, Shaw LJ, Pepine CJ, Reis SE, Kelsey SF, Sopko G, et al. Persistent chest pain predicts cardiovascular events in women without obstructive coronary artery disease: Results from the NIH-NHLBI-sponsored women's ischaemia syndrome evaluation (WISE) study. Eur Heart J 2006;27:1408-15.

179. Figueras J, Domingo E, Ferreira I, Lidon RM, Garcia-Dorado D. Persistent angina pectoris, cardiac mortality and myocardial infarction during a 12 year follow-up in 273 variant angina patients without significant fixed coronary stenosis. Am J Cardiol 2012;110:1249-55.

180. Brorsson B, Bernstein SJ, Brook RH, Werko L. Quality of life of patients with chronic stable angina before and four years after coronary revascularisation compared with a normal population. Heart 2002;87:140-5.

181. Bairey Merz CN, Handberg EM, Shufelt CL, Mehta PK, Minissian MB, Wei J, et al. A randomized, placebo-controlled trial of late $\mathrm{Na}$ current inhibition (ranolazine) in coronary microvascular dysfunction (CMD): Impact on angina and myocardial perfusion reserve. Eur Heart J 2016;37:1504-13.

182. Bairey Merz CN, Pepine CJ, Walsh MN, Fleg JL. Ischemia and no obstructive coronary artery disease (INOCA): Developing evidence-based therapies and research agenda for the next decade. Circulation 2017;135:1075-92. 